\section{DEMOCRACIA, REPRESENTACIÓN POLÍTICA, LIDERAZGOS Y LA CUESTIÓN INSTITUCIONAL. DISCUSIONES SOBRE LA TEORÍA Y PRÁCTICA DE LA POLÍTICA EN LAS DEMOCRACIAS CONTEMPORÁNEAS}

\author{
Hernán Fair \\ Consejo Nacional de Investigaciones Científicas y Técnicas \\ Universidad de Buenos Aires \\ herfair@hotmail.com
}

Cómo citar este artículo/Citation: Fair, H. (2016). Democracia, representación política, liderazgos y la cuestión institucional. Discusiones sobre la teoría y práctica de la política en las democracias contemporáneas. Arbor, 192 (781): a351. doi: http://dx.doi.org/10.3989/arbor.2016.781n5008

Recibido: 25 marzo 2015. Aceptado: 5 enero 2016

RESUMEN: Este trabajo analiza el problema de la representación política en las democracias contemporáneas, sus vínculos con el papel de los liderazgos políticos y la cuestión institucional. En una primera parte, examina los debates sobre la representación política desde las perspectivas predominantes de la Ciencia Política latinoamericana y las críticas desde las concepciones alternativas de la disciplina. En la segunda parte, se centra en la discusión teórica y práctica sobre las democracias representativas en la actualidad, examinando los vínculos y tensiones entre la teoría posfundacional del populismo de Laclau y la Ciencia Política neoinstitucionalista. En la última parte, realiza una crítica a la teoría laclausiana del populismo, distinguiendo conceptualmente entre los elementos institucionales, administrativos y pluralistas de la tradición liberal, que aparecen yuxtapuestos en el esquema laclauciano, y entre las formas populistas (posfundacionales) e ideológicas (fundacionales), a partir de las diferencias analíticas entre el autoritarismo, la dictadura y el totalitarismo. Luego, incorpora una serie de recursos de la tradición clásica de la democracia y del republicanismo, que se encuentran subteorizados en la perspectiva de Laclau. Finalmente, emplea estas herramientas para conceptualizar y analizar dos dimensiones, definidas como participativa-horizontal-popular y representativa-pluralista, tendientes a la construcción de una teoría posfundacional de la democracia radicalizada para el siglo XXI.

PALABRAS CLAVE: Representación política; democracia; liberalismo; teoría política posfundacional; ciencia política.

\section{DEMOCRACY, POLITICAL REPRESENTATION, LEADERSHIP AND THE INSTITUTIONAL QUESTION. DEBATES ON THE THEORY AND PRACTICE OF POLITICS IN CONTEMPORARY DEMOCRACIES}

Copyright: @ 2016 CSIC. Este es un artículo de acceso abierto distribuido bajo los términos de la licencia Creative Commons Attribution (CC BY) España 3.0.

ABSTRACT: This paper analyzes the problem of political representation in contemporary democracies, its links with the role of political leadership and the institutional issue. In the first part, it examines the debates on political representation from the predominant perspectives of Latin American political science and critiques from alternative views of the discipline. The second part focuses on representative democracies today, examining the links and tensions between Laclau's post-foundational theory of populism and neo-institutionalist political science. The last part critiques laclausian theory of populism, distinguishing conceptually between the institutional, administrative and pluralistic elements and the liberal tradition, which appears juxtaposed in the laclausian approach, and between the populist (post-foundational) and ideological (foundational) forms, on the basis of the analytical differences between authoritarianism, dictatorship and totalitarism. After that, some resources of the classical tradition of democracy and republicanism are incorporated, which are sub-theorized in Laclau's approach. Finally, these tools are used to conceptualize and analyze two dimensions, defined as participatory-horizontalpopular and representative-pluralist, which tend to construct a post-foundational theory of radical democracy for the twentyfirst century.

KEYWORDS: Political representation; democracy; liberalism; post-foundational political theory; political science. 


\section{INTRODUCCIÓN}

El presente trabajo se propone analizar uno de los debates más importantes de la teoría y práctica de la política contemporánea, relacionado al ejercicio de la representación política en las democracias contemporáneas, sus vínculos con el papel de los liderazgos políticos y la cuestión institucional. ¿En qué medida los liderazgos políticos pueden ser representativos? ¿Son los líderes populistas necesariamente democráticos o anti-democráticos? ¿Qué relevancia adquieren los mecanismos institucionales y pluralistas del liberalismo político y las formas republicanas para alcanzar una democracia consolidada? ¿Existe una disyunción estricta entre la concepción clásica de la democracia, con su visión participativa, popular y horizontal, y las concepciones representativas y pluralistas modernas? ¿En qué medida se han presentado mixturas y combinaciones a nivel teórico y conceptual y desde las experiencias histórico-políticas concretas? El siguiente trabajo analiza críticamente estas cuestiones centrales de la teoría, la filosofía y la praxis política contemporánea. En una primera parte, examina la temática de la representación política desde las perspectivas procedimentalistas y neo-institucionalistas que predominan en la Ciencia Política latinoamericana. Luego, analiza las críticas desde las concepciones alternativas de la disciplina, tomando como base el fenómeno de la "metamorfosis" de la representación de Manin y la propuesta teórica de Novaro. En la segunda parte, analiza las perspectivas de constructivismo social post-estructuralista de Lefort y Laclau. En el tramo final, se centra en la discusión teórica y práctica sobre las democracias representativas en la actualidad, examinando los vínculos y tensiones entre la teoría posfundacional del populismo de Laclau y la Ciencia Política neo-institucionalista. ¿En qué medida la teoría laclausiana del populismo se relaciona a una concepción democrática, autoritaria o anti-democrática?, ¿existen integraciones potenciales entre la teoría del populismo y las formas poliárquicas y pluralistas del liberalismo democrático?, ¿Qué vínculos se pueden establecer entre la teoría del populismo de Laclau y las perspectivas republicanas?

La hipótesis principal de este artículo consta de dos premisas:

1. La teoría posfundacional del populismo de Laclau presenta una concepción sobre la representación política que permite complejizar y enriquecer a las perspectivas predominantes de la Ciencia Política, al destacar el papel central de los liderazgos políticos como actores representativos, enfatizar en la dimensión afectiva del vínculo representativo y recuperar un imaginario social jacobino, propio de la concepción clásica de la democracia.

2. Sin embargo, al mismo tiempo adolece de un triple déficit teórico y conceptual en los aspectos democrático-populares, liberales y republicanos. Ello se debe a que relega (a) la conceptualización de los mecanismos de participación social horizontal del demos; (b) la conceptualización de las formas de pluralismo social y (c) la conceptualización de la dimensión institucional de la política, vinculada a la defensa de las libertades y derechos individuales, el Estado de derecho, la división de poderes y los frenos y contrapesos que limitan el poder decisionista del líder político.

3. Por último, se sostiene que estos déficits teóricos y conceptuales presentan serias implicancias normativas para la construcción de una teoría y una praxis de la política democrática radicalizada y plural del siglo XXI.

Como una respuesta a estos problemas teóricos y políticos, este artículo plantea una doble operación analítica:

a. Distinguir entre los elementos institucionales, administrativos y pluralistas del liberalismo político, que en la teoría del populismo de Laclau se presentan superpuestos.

b. Distinguir entre las formas populistas (posfundacionales) e ideológicas (fundacionales), tomando en cuenta los gradientes diferenciales entre el autoritarismo, la dictadura y el totalitarismo.

Luego, incorpora a la discusión algunas herramientas teóricas vinculadas a la tradición clásica de la democracia, al liberalismo político y al republicanismo, que se encuentran subteorizados en la obra laclausiana. A partir de allí, conceptualiza dos dimensiones de análisis, definidas como (1) participativa-horizontalpopular y (2) representativa-pluralista. Finalmente, propone una integración óntica de estas dimensiones para el análisis político de las democracias actuales.

Mediante el desarrollo de esta conceptualización se espera contribuir a la construcción de una teoría y una praxis política posfundacional de la democracia radical y plural para el siglo XXI. Básicamente, se procura aportar recursos a la discusión teórica y práctica sobre la democracia y los liderazgos políticos en el mundo actual, con la meta puesta en la necesidad de radicalizar 
los aspectos igualitarios, participativos y pluralistas de la democracia, evitando el riesgo de repetir las experiencias burocráticas, elitistas, autoritarias y totalitarias del pasado, aunque sin caer en un procedimentalismo parlamentarista o en un tecnocratismo gestionario, que reduzca el valor de la democracia a sus aspectos meramente formales, técnicos e institucionales.

\section{EL FENÓMENO DE LA CRISIS DE REPRESENTACIÓN POLÍTICA DESDE LAS PERSPECTIVAS PREDOMINAN- TES DE LA CIENCIA POLÍTICA}

Desde finales de los años '80 las perspectivas predominantes de la Ciencia Política latinoamericana, de matriz teórica neo-institucionalista, se han referido a la existencia de una "crisis de representación" o "crisis de representatividad" de los partidos políticos tradicionales y del Congreso. En primer lugar, se ha destacado que, en contraste con los países europeos centrales, en gran parte de América Latina no se extendió una cultura política democrático-liberal y deliberativa, adquiriendo la representación política una lógica de fuerte personalización del poder en los liderazgos "populistas" y su matriz movimientista y unanimista, lo que impidió el funcionamiento de un sistema de partidos pluralista y estable ${ }^{1}$.

En segundo término, se ha enfatizado en las prácticas de los liderazgos políticos latinoamericanos, que actuaron históricamente en tensión con los valores de la democracia liberal y rechazaron los controles institucionales. El ejercicio del poder basado en el "personalismo hegemónico" de estos liderazgos "populistas" no respetó la división funcional de poderes, ni fomentó el diálogo plural, erosionando los aspectos deliberativos y el resguardo de los derechos y libertades individuales (en particular, la libertad de prensa y de expresión) y del Estado de Derecho (Botana, 2006, p. 27 y ss.).

Durante los años '90 se extendieron desde la Ciencia Política las críticas a las democracias "delegativas" (O’Donnell, 1992) y a las formas de decisionismo político de los presidentes, destacando el papel "autoritario" y "demagógico" de los nuevos liderazgos regionales (en particular, con los ejemplos de Menem en Argentina, Collor de Mello en Brasil y Fujimori en Perú), a partir del abuso de los poderes de prerrogativa, la aversión a respetar la división de poderes, los mecanismos de control institucional y las libertades individuales que permiten recrear una democracia "formalmente institucionalizada" (O’Donnell, 2001). Se ha señalado, además, que estos liderazgos "delegativos" profundizaron la crisis de representación de los parti- dos políticos y del Parlamento y promovieron la "despolitización" social de la ciudadanía (Garretón, 1998).

El rechazo de las concepciones predominantes de la Ciencia Política a la representatividad de los liderazgos políticos tendió a reducir el vínculo político con las masas populares a un pretendido carácter irracional, demagógico y puramente manipulativo². La mayor parte de las corrientes liberales y procedimentales, sin embargo, destacan que todo liderazgo político es, por definición, no representativo, ya que la representación democrática requiere de la presencia de una pluralidad de voces que debatan o deliberen racionalmente en el Parlamento. En ese marco, ha sido notable el impacto de la obra del jurista Hans Kelsen, cuyo formalismo positivista partía de la base que una democracia representativa se caracteriza por el gobierno impersonal de las leyes, siendo el titular del poder la norma (Novaro, 2000, p. 99). También debemos destacar la influencia central de la teoría de la "democracia delegativa” de O'Donnell (1992). Desde esta perspectiva, la capacidad decisoria de los liderazgos, al actuar de forma personalista y no promover los mecanismos de deliberación institucional y de control político del poder ("accountability"), atentan contra la consolidación de la democracia representativa. Finalmente, la clásica tipología de Sartori (1980) sobre los sistemas políticos acentuó la crítica a los partidos "hegemónicos" que concentran el poder en el Ejecutivo y los aportes desde la política comparada pusieron en evidencia el contraste con determinados países europeos en los que predominan las formas coalicionales y el respeto a los mecanismos institucionales y pluralistas de la democracia "consociativa" (Lijphart, 1984).

A partir de estas contribuciones, en los años '90 emergió un sub-debate dentro de la disciplina en el que una serie de politólogos señalaban que el problema de la crisis de representación política en América Latina se vinculaba a la existencia del sistema presidencialista. En contraste con los sistemas parlamentaristas europeos, autores como Linz y Valenzuela destacaban que el presidencialismo reforzaba la personalización del poder en el Ejecutivo y los rasgos plebiscitarios y desincentivaba la construcción de acuerdos institucionales amplios y coaliciones sociales duraderas. De este modo, el sistema electoral fomentaba la presencia de un juego de suma-cero a favor del Presidente y una disputa de fuerzas con la oposición parlamentaria que, cuando existía un Gobierno con minoría parlamentaria, generaba un bloqueo en la toma de decisiones e impedía la conformación de una democracia estable y consolidada ${ }^{3}$. 


\section{LA METAMORFOSIS DE LA REPRESENTACIÓN POLÍ- TICA Y EL PAPEL CENTRAL DE LOS LIDERAZGOS DESDE LA CIENCIA POLÍTICA NO INSTITUCIONALISTA}

Diferenciándose de las perspectivas predominantes de la Ciencia Política, Bernard Manin (1992) acuñó el concepto de "metamorfosis" de la representación política para destacar que, en las últimas décadas, antes que a una crisis de representatividad, asistimos a una metamorfosis del vínculo político, a partir de la creciente "personalización" de la política y el papel central que adquieren los líderes políticos y su capacidad de construir imágenes simplificadas desde los medios masivos de comunicación. En el marco de un proceso más amplio de mediatización de la política, esta perspectiva sostiene que la tradicional democracia de partidos "muta" hacia una "democracia de lo público", en el que los actos partidarios y los largos discursos programáticos pierden influencia y la oferta electoral de los liderazgos políticos adquiere un rol central, en base a la construcción de imágenes que se galvanizan desde la pantalla del televisor (Manin, 1992).

Junto a la creciente mass-mediatización, esta metamorfosis de la representación política ha sido vinculada a los cambios generados por las reformas neoliberales y el proceso de interconexión mundial conocido como globalización, que fragmentaron y complejizaron las identidades políticas y sociales. Además, se ha destacado la crisis de acumulación y de legitimación del Estado Benefactor y el derrumbe del socialismo soviético, que condujeron a una crisis de los grandes relatos movilizadores y promovieron sentimientos de frustración y decepción hacia las instituciones políticas (Novaro, 1994, p. 20). Ello reforzó la función "formativa" de las intervenciones políticas, en desmedro de la función "agregativa" de los marcos institucionales tradicionales ${ }^{4}$ (Novaro, 2000, pp. 26-27 y ss.).

\section{LAS CRÍTICAS DESDE LA TEORÍA POLÍTICA CON- TEMPORÁNEA}

La Ciencia Política neoinstitucionalista y procedimentalista tendió a menospreciar y rechazar el papel central que adquieren los liderazgos políticos en el proceso de representación democrática, acusándolos de delegativos, autoritarios y anti-representativos y contraponiéndolos a la defensa del gobierno de la ley, la división de poderes y el modo de funcionamiento del sistema de partidos del parlamentarismo.

Las perspectivas críticas provenientes desde la teoría política contemporánea recuperaron las diatribas de Carl Schmitt contra el parlamentarismo y contra el propio Kelsen, recordando que las leyes requieren de la aplicación de los hombres, quienes no sólo las instituyen, sino que deben decidir sobre su aplicación en los casos concretos. La teoría decisionista schmittiana sostiene que lo que caracteriza al líder político es la capacidad "soberana" de "decisión", en particular en los "momentos de excepción" (Schmitt, 2005). Esta capacidad decisoria de los liderazgos, con antecedentes en la obra de Weber (1984), condujo a Schmitt a destacar el papel central del líder político, a través de sus decisiones y acciones existenciales, para garantizar la unidad jurídico-política de la Nación, frente a la "charlatanería" y el "diletantismo" de los partidos políticos que competían en el Parlamento alemán ${ }^{5}$.

Durante los años '90, una porción de la teoría política no institucionalista recuperó de forma pragmática los aportes de la teoría decisionista schmittiana para cuestionar la "noción estrecha de la representación" (Novaro, 1994, p. 26) de las perspectivas procedimentales y pluralistas y destacar que los líderes políticos podían ser representativos y conservar una amplia legitimidad social. Autores como Marcos Novaro señalaron, en ese sentido, que en las últimas décadas presenciamos el surgimiento de una "nueva política", signada por el debilitamiento de las identidades partidarias e ideológicas y el simultáneo "reforzamiento y redefinición de los liderazgos y sus funciones representativas" (Novaro, 2000, p. 57). En el marco del derrumbe del proyecto socialista como alternativa global al capitalismo, la mayor fragmentación y heterogeneidad de la estructura social y el papel central que adquieren los mass media, se produce un debilitamiento de las identidades políticas de fuerte antagonismo que predominaban en la posguerra y una creciente volatilidad electoral, que acentúan el papel "formativo" de la representación mediante liderazgos, el cual adquiere un mayor alcance y gravitación (Novaro, 2000, p. 65 y p. 71). Los líderes políticos, en efecto, son capaces de generar confianza y de unificar simbólicamente a la fragmentada sociedad con sus interpelaciones y sus decisiones políticas escenificadas a nivel mediático (Novaro, 1994). Emergen, de este modo, nuevas identidades globalizantes o "por escenificación", que predominan sobre las puramente antagonistas o "por alteridad", típicas de las democracias de partidos. De acuerdo a Novaro, aunque las decisiones y acciones del Ejecutivo relegan la función agregativa de los partidos políticos, las identidades por escenificación de los liderazgos logran unificar y "repolitizar" al conjunto de la ciudadanía en torno a ciertas ideas aglutinantes que son personificadas por determinadas figuras representativas (Novaro, 2000, p. 60 у pp. 238-248). 
Tomando como base el caso argentino durante los años '90, este autor destaca que la crisis de representación de las organizaciones institucionales y de "despolitización" de gran parte de la ciudadanía, fue acompañada por un proceso inverso de "repolitización" social y de "recomposición de los vínculos" de representación política en torno al liderazgo "ejecutivista" de Carlos Menem (1989-1999). En el marco de la situación de emergencia económica y social de fínales de los '80 (hiperinflación, saqueos a comercios y supermercados), Menem construyó un nuevo estilo de liderazgo político que, ya desde la campaña presidencial, personalizó el vínculo político en torno a su persona ("Síganme, no los voy a defraudar!") $y$, una vez en el poder, apeló a la situación de caos e ingobernabilidad para legitimarse como "piloto de tormentas" y único garante de la gobernabilidad y el orden social. El vínculo personalizado se fortalecía con las decisiones y acciones concentradas en el Ejecutivo y con sus constantes apariciones públicas haciendo deportes, mostrando un estilo canchero y seductor con las mujeres y evidenciando una cómoda adecuación a los medios masivos de comunicación, donde se acentuaba su figura carismática. Finalmente, el liderazgo de Menem apelaba a una estrategia interpelativa "neopopulista", que destacaba la necesidad de actualizar, adaptar y adecuar a la "antigua" identidad peronista de posguerra a los "nuevos tiempos" de identidades "por escenificación", legitimando su discurso de la unidad nacional y su giro hacia el neoliberalismo y el realismo de las "relaciones carnales" (Novaro, 1994).

Situados en un punto de intersección, otros autores reformularon la teoría del decisionismo y la articularon con elementos de la teoría delegativa y con la "estrategia neopopulista" de los liderazgos emergentes, para destacar la construcción de una novedosa matriz ideológico-política "neodecisionista". Esta matriz condensaba a algunos liderazgos fuertes de América Latina, entre ellos Menem, Collor de Mello y Fujimori, que se legitimaron políticamente y adquirieron representatividad mediante un estilo político personalista y ejecutivista, cuya performance les permitía situarse como garantes de la recuperación del orden público y la paz social, frente a un pasado de caos y anomia social, al tiempo que despreciaban la división de poderes. A diferencia de la teoría decisionista schmittiana, aplicada durante el nazismo en Alemania, lo que caracterizaba a los nuevos liderazgos ejecutivistas de la última década del siglo XX era la atenuación, en lugar de la total eliminación, de los mecanismos institucionales del Estado de Derecho. En segundo término, la extensión del decisionismo como un "estilo de gobierno" que hacía del "estado de excepción" una "norma", de manera tal de reforzar la legitimidad presidencial para el (ab)uso de los poderes de prerrogativa (centralmente, a través de los decretos de necesidad y urgencia y los vetos parciales o totales). Por último, la implementación de políticas neoliberales y neoconservadoras tendientes a "desmontar el aparato estatal regulador y prestador de servicios", antes que a promover el "estatismo" del Estado Benefactor (Leiras, 2008; Baldioli y Leiras, 2010, pp. 44-51).

Desde una concepción posfundacional basada en la teoría post-estructuralista francesa, Aboy Carlés (2001) destacó también el reduccionismo de las perspectivas normativistas y liberales de la Ciencia Política para analizar y comprender el proceso de representación política en las democracias actuales, enfatizando en el papel constitutivo del orden simbólico en la construcción del vínculo de representación política y en la capacidad de reformulación histórica de las identidades políticas. Además, identificó a la "representación" como una dimensión constitutiva de las identidades políticas, vinculándola a la construcción de un "campo de solidaridades" y de "homogeneización interna" y subrayó la dimensión ontológica de la "alteridad". Finalmente, destacó la dimensión de la "tradición", afirmando que la construcción de las identidades políticas se estructura sobre la base de un campo "parcialmente sedimentado y objetivado" que limita el margen de opciones posibles (Aboy Carlés, 2001, pp. 21-74).

\subsection{Las dos dimensiones del proceso de represen- tación política en las democracias contemporáneas}

Desde la teoría y la filosofía política moderna predominaron históricamente dos enfoques sobre el proceso de representación política. Por un lado, la concepción hobbesiana, que parte de la base de autonomizar absolutamente el papel del representante, para imponer de forma arbitraria el orden público (la paz social), concluyendo con la "guerra de todos contra todos". Por el otro, la concepción rousseauniana, que rechaza el concepto de representación política y asume una visión centrada en el auto-gobierno del pueblo como único soberano legítimo.

Desde la primera perspectiva, aunque sin la visión contractualista y su acto original de autorización, se desarrollaron enfoques autoritarios y anti-liberales sobre el vínculo de representación política (Schmitt), o concepciones que destacan el papel aglutinante y decisorio del liderazgo, sin desconocer el rol repre- 
sentativo del Parlamento y reconociendo una mayor autonomía a los representados ${ }^{6}$ (Weber, Heller, Leibholz). Desde el segundo enfoque, en cambio, se destacaron distintas visiones de la democracia deliberativa (Arendt, Habermas), que rechazan el papel de las mediaciones institucionales y personalistas de la representación política (Novaro, 2000, p. 88 y ss.).

La disyunción estricta entre representación política y participación social ha sido superada por una pluralidad de perspectivas recientes que, reconociendo la inevitabilidad de determinados vínculos representativos en las democracias contemporáneas (una cuestión que el propio Rousseau señalaba), destacan que la representación política no puede ser reducida a la expresión o agregación de intereses, demandas o voluntades previamente existentes en los representados, ni tampoco a una autonomía absoluta del representante político para la toma de decisiones. En esta línea, se ha señalado la existencia de "un continuum de formas intermedias entre la democracia directa y la representativa" (Bobbio, 1993, p. 40), incluyendo el análisis de diversos mecanismos de democracia semidirecta y de participación comunitaria institucionalizada (Schneider y Welp, 2011).

Como indica Novaro (2000), la representación democrática mediante liderazgos posee dos dimensiones entrelazadas. Por un lado, existe una dimensión "descendente", que corresponde al proceso de re-presentación, que permite hacer presente (re-presentar) lo ausente (lo representado) mediante la dinámica de representación política de los liderazgos, es decir, mediante los imaginarios unificantes y las decisiones y acciones ejecutivas del líder. Ello implica, siguiendo a Schmitt, la capacidad de adquirir una "autoridad representativa", a través de "decisiones políticas concretas y contingentes" que "crean" autoridad y generan un ordenamiento social efectivo en la comunidad. Por el otro, existe una dimensión "ascendente" del vínculo representativo, vinculada al proceso inverso que va desde los representados hacia el representante. En este punto el autor recupera algunos aportes de Weber (1984) referidos a la necesaria legitimidad del vínculo representativo (aunque sin subsumirlo a su concepción subjetivista) (Novaro, 2000, pp. 93-97).

Pese a que, como indica Novaro, el pensador alemán "no desarrolla una verdadera teoría de la representación" (Novaro, 2000, p. 130), sí señala que el representante político debe ser "reconocido" como válido (legítimo) por los representados (Weber, 1984). La representatividad "ascendente" del líder se vincula, en ese sentido, tanto a su capacidad para "repre- sentar ideas y virtudes valoradas por los ciudadanos" (Novaro, 2000, p. 186), como a la "aprobación interna" de las masas, quienes se "identifican" con el líder, asumiendo "su poder como propio" (Novaro, 2000, p. 109). En dicho marco, para Novaro la dimensión "ascendente" refiere a la posibilidad de un "juicio sobre los actos de gobierno" por parte de los representados, entendidos como "opinión pública", sin que ello implique adoptar la tesis positivista de la "fidelidad a la opinión pública” (Novaro, 2000, p. 187).

En las democracias representativas actuales esta capacidad de enjuiciamiento público a los actos y decisiones del representante político, que dan sentido a la noción de "responsabilidad", contiene dos ejes que se relacionan con el respeto al "pluralismo institucional". Por un lado, "el control que debe ejercer el Parlamento sobre el Ejecutivo", vinculado al resguardo a la división republicana de poderes. Por el otro, "el control de la opinión pública sobre ambos", tanto a través del voto libre, como mediante el derecho a expresar públicamente los reclamos ante los representantes (Novaro, 2000, pp. 79, 196-202).

\section{LAS CRÍTICAS DESDE LAS CONCEPCIONES CONS- TRUCCIONISTAS DE LA REPRESENTACIÓN POLÍTICA}

Una segunda crítica a las visiones neo-institucionalistas y procedimentalistas de la Ciencia Política proviene de las perspectivas construccionistas sociales vinculadas al post-estructuralismo. Estas perspectivas toman como base la crítica que Derrida (1989) retoma de Heidegger a la "metafísica de la presencia", para enfatizar en la imposibilidad de una realidad social carente de su representación simbólica y señalar el "plus" que necesariamente incorpora el representante en el proceso de representación política y la inherente dimensión pragmática y performativa del orden significante, en tanto construcción de carácter contingente, histórica y material. De este modo, cuestionan a las perspectivas esencialistas, objetivistas y subjetivistas y, al mismo tiempo, se distinguen de las visiones representacionialistas y existencialistas, enfatizando en el rol constituyente del orden significante en la construcción social del vínculo representativo. Desde la teoría política posfundacional, se destacan dos visiones acerca de la dinámica de representación política de lo social: la de Claude Lefort y la de Ernesto Laclau.

\subsection{La perspectiva de Claude Lefort}

Partiendo de la imposibilidad de la plena presencia de lo social, el teórico y filósofo político francés Claude Lefort (1990 y 2011) incorpora dos elementos centra- 
les a la discusión. En primer lugar, desde los aportes de la teoría política de Maquiavelo (1998), enfatiza en el aspecto constitutivamente conflictivo, antagónico y contingente del proceso de representación política. En ausencia de esencias o fundamentos últimos, el orden social en la Modernidad pasa a ser producto de la "contingencia" e "indeterminación" de lo social y del carácter político que lo instituye, no siendo posible una representación absoluta y total de lo social. En segundo término, desde Tocqueville (1969), incluye una defensa política de las libertades individuales y la pluralidad de lo social, sin descuidar el resguardo de los aspectos participativos y sociales de la democracia.

Mediante los aportes de Maquiavelo, Lefort logra trascender la clásica disyunción entre Hobbes y Rousseau, incluyendo a las concepciones jacobinas, socialistas y schmittianas y sus derivaciones históricas totalitarias (de izquierda o de derecha), para analizar una forma de representación política alternativa que reconoce el elemento inherentemente conflictivo, antagónico y contingente de lo social. Las contribuciones de Tocqueville, por su parte, le permiten cuestionar a las visiones procedimentales del liberalismo político, entendiendo a la democracia no como un régimen formal, sino como un tipo de sociedad que tiende a la igualación progresiva de las condiciones sociales, aunque al mismo tiempo debe evitar el peligro de la "tiranía de las mayorías"7.

De manera tal que lo que Lefort denomina la "representación democrática", en oposición al poder monárquico o aristocrático, tiene por objeto:

Exhibir delante de todos, los motores y los resultados de la deliberación pública, tornar legible la confrontación de las posturas que se engendran de la diversidad de los intereses y de las opiniones en el seno de la sociedad (Lefort, 2011, p. 22).

Para el teórico francés, la "representación institucionalizada" requiere del reconocimiento legítimo de la apertura de lo social y la aceptación del pluralismo, de manera tal que:

La representación no puede ser fecunda, a menos que venga a arraigarse en cierto suelo, a inscribirse en un espacio social vivo, en el cual circule la información, en el cual puedan expresarse múltiples opiniones, en el cual, por último, pueda haber, para grupos e individuos diferentes, una sensibilidad a intereses y aspiraciones que no sean los suyos. En suma, la representación requiere el establecimiento de un espacio público tal que pueda efectuarse una modificación mutua de los puntos de vista y que la opinión pública pueda reconocer la legitimidad de nuevos derechos (Lefort, 2011, p. 25).
Pero además, en un último movimiento, Lefort integra algunos elementos derivados del humanismo rousseauniano ${ }^{8}$. En ese marco, con el objeto de radicalizar la concepción sobre la "revolución democrática" de Tocqueville, se refiere a la importancia central que asume el respeto de los Derechos Humanos, entendidos no como un ideal regulativo ligado a cuestiones morales, ni como un mero procedimiento para defender el individualismo burgués, sino como un concepto "claramente político" (Lefort, 2011, p. 76) que permite valorar y hacer posible el cumplimiento fáctico de los derechos individuales y sociales de los seres humanos, en un sentido amplio. Lefort destaca, así, que los Derechos Humanos deben ser entendidos como derechos que hacen al individuo como ser social, en tanto corresponden a "individuos que siempre son individuos sociales", ya que se insertan en una "red de relaciones" y en una trama de socialización (Lefort, 2011, pp. 77-80 y ss.).

Estos derechos, tal como han sido tipificados en las Constituciones Nacionales y en la Declaración Universal de los Derechos Humanos de 1948, le permiten a los seres humanos tener un derecho efectivo a la participación social en la autodeterminación de las decisiones colectivas, a expresarse públicamente y de forma plural en el espacio público, a decidir libremente su religión y su propia orientación sexual, a disentir y oponerse públicamente a las decisiones arbitrarias y autocráticas emanadas del líder político y a denunciar y juzgar las formas de opresión social del poder estatal, la explotación imperialista y la dominación patriarcal. Pero además, el respeto a los Derechos Humanos implica el reconocimiento de las "necesidades elementales de los oprimidos" (Lefort, 2011, p. 75), como el derecho económico y social al trabajo, a tener seguridad social y a disponer de un salario digno y justamente remunerado (Lefort, 1990 y 2011). En ese sentido, para Lefort no alcanza con la "ideología del liberalismo", sino que la democracia requiere "formular un programa claro de limitación de los efectos de la pobreza" y ser acompañado por "un verdadero combate contra el fenómeno de la exclusión", haciéndose cargo de "las necesidades y las aspiraciones de la inmensa mayoría” (Lefort, 2011, p. 31).

A partir de estas contribuciones, que pretenden mostrar el potencial contraste entre los ideales declamativos (ideales de libertad, igualdad, justicia, emancipación social), y sus aplicaciones (y posibles desviaciones) histórico-políticas (el "Terror" jacobino, el socialismo soviético real, las dictaduras militares, el fascismo italiano y el nazismo ${ }^{9}$ ), Lefort distingue 
a nivel analítico entre las tradiciones democráticas y liberales, para luego plantear una integración que busca efectivizar los ideales socialmente igualitarios, participativos y populares de la concepción clásica de la democracia, aunque sin desconocer los aspectos institucionales y pluralistas que caracterizan a la "democracia representativa" moderna. Ello incluye tanto la defensa irrestricta de las libertades civiles, como de los Derechos Humanos básicos y fundamentales de los ciudadanos, lo que supone, como precondición, la "desincorporación del poder" y, por lo tanto, la aceptación de la "contingencia" e "indeterminación" que caracteriza a todo orden social, desde un pensamiento posfundacional (Lefort, 2011, pp. 19-20 y ss.).

A partir de estas contribuciones, Lefort asume la famosa tesis del "lugar vacío" del poder, lo que implica que, en ausencia de fundamentos últimos, la representación política nunca puede ocupar de forma plena y absoluta lo social. De este modo, ningún representante político puede arrogarse legítimamente la representación del Pueblo como un cuerpo que encarna la totalidad (el "Pueblo-Uno"), ni tampoco concentrar el poder de forma unipersonal. A partir de ahora, el poder se distingue de la ley y del saber y el cuerpo social sólo puede instituirse de forma simbólica y de manera indeterminada. Ello garantiza la distinción entre el Estado y la sociedad y hace posible, en su crítica a los totalitarismos (de izquierda y de derecha), el resguardo de las libertades individuales, en un doble sentido negativo y positivo (en los términos de Berlin) (Lefort, 1990 y 2011).

\subsection{La teoría de la representación política de Ernes- to Laclau}

Las contribuciones de Derrida y de Lefort (junto a los aportes de la teoría lacaniana y el concepto gramsciano de hegemonía) influyeron de forma notable en la teoría política posfundacional de Ernesto Laclau. Desde sus textos de la primera mitad de los años '80, Laclau reconoce (junto a Mouffe) la imposibilidad ontológica de la plena presencia de lo representado y la contingencia radical de lo social que caracterizan a la Modernidad. En este sentido, el teórico político destaca que la representación de lo social nunca es "transparente", y recupera las contribuciones de Lefort, vía Tocqueville, para referirse a la tesis de la "revolución democrática", basada en la existencia del "lugar vacío" del poder, la ausencia de fundamentos últimos y sustanciales y, como derivación, el reconocimiento de la "pluralidad e indeterminación de lo social" (Laclau y Mouffe, 1987, p. 194 y ss., en particular pp. 232-233).
Sin embargo, a diferencia de estos autores, en sus trabajos de los '80 Laclau realiza una deconstrucción genealógica que recupera y reformula, en clave "posmarxista", el concepto de hegemonía, para vincularlo al post-estructuralismo. A partir de allí, construye una novedosa teoría posfundacional de la hegemonía que supone, en sus palabras, partir de "un campo teórico dominado por la categoría de articulación" (Laclau y Mouffe, 1987, p. 129). Cuestionando el esencialismo económico marxista (incluyendo al propio "reducto esencialista" gramsciano), Laclau sostiene que la hegemonía debe ser entendida como una "práctica articulatoria" que "modifica también la naturaleza de lo que es representado" (Laclau y Mouffe, 1987, p. 90). Teniendo en cuenta la "complejización y fragmentación creciente de las sociedades industriales avanzadas" y la "creciente proliferación de diferencias", la "práctica articulatoria" resulta central, ya que "constituye y organiza las relaciones sociales" (Laclau y Mouffe, 1987, pp. 132-133). En ausencia de un "centro que aglutine el poder, a la ley y el saber", resulta "posible y necesario unificar ciertos espacios políticos a través de articulaciones hegemónicas", articulaciones que "serán siempre parciales y sometidas a la contestación, puesto que ya no hay garante supremo" (Laclau y Mouffe, 1987, p. 234).

En sus trabajos de los años '90, Laclau profundiza en los aportes de la deconstrucción para sostener que en todo proceso de representación el representante político necesariamente incorpora, desde el orden simbólico, determinados intereses y demandas (no pre-constituidas) hacia lo representado. En efecto, debido a que la representación se realiza en un lugar que se encuentra ausente, el representante político inevitablemente incorpora un agregado o "plus" a aquello que representa. Ello impide la pura expresión de intereses o mandatos previos a su enunciación. Como señala en "Nuevas reflexiones sobre la revolución de nuestro tiempo":

Por un lado, la representación, para ser tal, no puede operar enteramente a espaldas del representado. Por el otro, para ser realmente una representación, ella requiere la articulación de algo nuevo que no está dado simplemente por la identidad del representado (Laclau, 1993, p. 55).

Basándose en la crítica derridiana a Rousseau, Laclau destaca en esta etapa que "no hay una representación que transmita de forma perfecta o transparente la voluntad de aquellos a quienes representa", ya que ello supondría una "identificación completa 
del representado con su voluntad" (Laclau, 2005b, p. 101). Las identidades, en efecto, son siempre "suplementadas por el representante" quien, necesariamente, "contribuirá en algo a las identidades" de los representados (Laclau, 1996, p. 154; Laclau, 2005b, p. 102). Este fenómeno se potencia en los procesos políticos contemporáneos, signados por una mayor fragmentación de las identidades sociales. En ese sentido, Laclau sostiene que:

La fragmentación de las identidades sociales requiere de formas de agregación política, cuya constitución implica que los representantes desempeñan un papel activo en la formación de voluntades colectivas, en vez de ser sólo el espejo pasivo de intereses preconstituidos en el nivel de la sociedad civil (Laclau, 2005b, p. 103).

La necesidad de todo representante político de "tomar decisiones que afectarán los intereses de alguien que estará materialmente ausente" (Laclau, 2003a, p. 213), conducen a Laclau a concluir, desde una concepción posgramsciana, que "la hegemonía presupone formas de representación" (Laclau, 1996; Laclau, 2003a, pp. 209 y 214) y, por lo tanto, que "sin representación, no hay hegemonía” (Laclau, 2003b, p. 113), de modo tal que "la representación es constitutiva de la relación hegemónica” (Laclau, 2003b, p. 62).

Sin embargo, el pensador argentino incorpora un aporte adicional, al afirmar que todo representante, desde la dinámica política, debe "efectivamente representar" a sus representados, es decir, debe pretender ser "representativo". De esta manera, si bien el ejercicio de la representación política siempre incorpora un "plus" que es capaz, bajo ciertas condiciones, de performar (crear discusivamente) una nueva realidad, reformulando las demandas sociales existentes, e incluso "creando" nuevas demandas (Barros, 2006), el representante político no puede volverse totalmente autónomo de aquellos sectores sociales a quienes representa (Laclau, 1993). Finalmente, como no existe un fundamento que pueda encarnar la totalidad de lo social, toda representación será, necesariamente, "parcial", ya que "tendrá lugar sobre el fondo de una irrepresentabilidad esencial” (Laclau, 1996, p. 29).

Durante esta etapa de los años '90 Laclau realiza una innovación fundamental, al vincular la representación política al rol que ejercen los "significantes vacíos" en la dinámica política. Luego de rechazar a las propuestas ultra-particularistas (posmodernas, nietzscheanas) y universalistas (platónicas, hobbesianas, hege- lianas), el pensador argentino destaca la existencia de determinados significantes privilegiados que logran trascender coyunturalmente su inherente particularidad para encarnar simbólicamente la universalidad ausente. Lo que Laclau define como la "operación hegemónica" consiste, precisamente, en el desplazamiento metonímico de determinados significantes primordiales que logran trascender su inherente particularidad y universalizarse de forma tendencial para encarnar exitosamente la "plenitud comunitaria ausente" (Laclau, 1996, p. 82). Necesariamente, se trata de una forma de universalidad "relativa" y "parcial" del "orden comunitario", en el momento en que toda hegemonía mantiene siempre presente una dimensión inherente de "particularidad" y "diferencialidad", vinculada al carácter "contingente", "precario" y "parcial" del orden social (Laclau, 1996).

Mediante estas contribuciones, Laclau se distingue de la visión de Lefort, para quien "la democracia moderna aparece como el régimen en el cual el lugar del poder es inocupable" (Lefort, 2011, p. 148). Para el teórico argentino, en cambio, el "lugar vacío" del poder puede ser ocupado de forma precaria, relativa y parcial, a través de determinados significantes de vacuidad tendencial (democracia, justicia, igualdad, etc.), que logran simbolizar la unidad del orden comunitario ausente, manteniendo vigente un residuo inherente de particularidad y diferencialidad. La operación hegemónica es la capacidad de determinado proyecto político de trascender simbólicamente su particularidad inherente para encarnar la universalidad del orden social.

En esta etapa, además, Laclau se distingue de la propuesta deconstructivista derridiana, al incorporar una dimensión "representativa", que toma en cuenta cierta voluntad (no preconstituida) de aquellos a quienes el representante político debe representar, sin desconocer el "plus" que necesariamente incorpora todo representante. En este sentido, recupera algunos elementos de la fenomenología existencialista para indicar que toda representación política se inscribe en el marco de la existencia de "objetividades sedimentadas" (Laclau 1993, p. 177) que limitan contextualmente el margen de opciones de la construcción hegemónica. De este modo, el teórico político argentino complejiza a las vertientes constructivistas y post-estructuralistas, edificando una teoría de la representación política democrática que trasciende a las visiones particularistas, universalistas y esencialistas, sin caer en un decisionismo extremo, ni en un procedimentalismo liberal $^{10}$. 


\subsubsection{La representación política en la teoría posfun- dacional del populismo}

A partir de la elaboración de la teoría posfundacional del populismo, Laclau (2005a) inició una última etapa en su obra. En consonancia con sus textos previos, en esta etapa Laclau reconoce que "está en la naturaleza de la representación el hecho de que el representante no sea un mero agente pasivo, sino que deba añadir algo al interés que representa" (Laclau, 2005a, p. 200). De este modo, señala la imposibilidad de la plena presencia de lo representado y el papel simbólico formativo del representante político. Al mismo tiempo, para evitar reducir la representación política a una absoluta autonomía decisoria y performativa del representante, destaca la necesidad de todo representante político de procurar ser "representativo", reconociendo cierta "voluntad" social (no preconstituida ni plena) de aquellos sectores a quienes representa (Laclau, 2005a, pp. 205-207). Sin embargo, Laclau incorpora cuatro elementos adicionales a su esquema:

1. Destaca el papel central que asume la figura individual del líder populista en el proceso de representación política.

2. Se refiere a la necesidad de partir del concepto de "demandas sociales insatisfechas" como "unidad mínima" de todo análisis político.

3. A partir del punto anterior, vincula la representatividad del líder populista a la satisfacción equivalencial de las demandas sociales del "pueblo", en el sentido de la integración discursiva al sistema político de las demandas no reconocidas de "los de abajo".

4. Enfatiza en el rol del "afecto" y las "ligazones catexiales" en torno a los liderazgos populistas.

Estas innovaciones implicaron una serie de reformulaciones parciales en su perspectiva constructivista de la representación política. Desde el lado del representante, Laclau destacó:

a. La relativa autonomía que adquiere la figura y el nombre del líder populista, entendido no como una mera "posición de sujeto", sino como un cuerpo y una individualidad (Laclau, 2005a, p. 130), que asume una parcial independencia de las restricciones estructurales.

b. La capacidad del líder populista de tomar decisiones, representar y articular equivalencialmente a una pluralidad de "demandas sociales insatisfechas" de "los de abajo" en el proceso de representación política, actuando, en última instancia, como eje (parcial) articulador del "orden comunitario" ausente ${ }^{11}$.

c. Como consecuencia de los puntos anteriores, la revalorización del líder político como una figura potencialmente representativa, democráticopopular y legítima.

Desde el lado de los representados, podemos destacar las siguientes innovaciones:

a. La revalorización del significante pueblo como modo primordial de simbolizar y articular políticamente a los representados.

b. La incorporación del concepto de demandas sociales insatisfechas como eje del análisis político, lo que permite reforzar la relativa autonomía del demos y la pretensión representativa y popular de los liderazgos políticos.

c. Como consecuencia de los puntos anteriores, la revalorización de un "imaginario jacobino" (Aboy Carlés, 2010), si bien desligado de su concepción contractualista, que realza aspectos de la concepción clásica de la democracia (y con ella, a los sectores populares) frente a la denigración histórica del pueblo y de lo popular por parte de las teorías neoconservadoras y elitistas de la Ciencia Política y la sociología.

d. La ligazón afectiva que articula a los representados con los representantes políticos, vinculada a las identificaciones sociales en torno a ciertos objetos parciales que asumen un imaginario de universalidad y la investidura catexial en torno a la figura del líder populista ${ }^{12}$.

\subsubsection{El doble movimiento de la representación poli- tica en la teoría de Laclau}

En consonancia con la propuesta de representación "ascendente" y "descendente" que ya había destacado Bobbio (1993), aunque desde una perspectiva de constructivismo social post-estructuralista, la teoría política de Laclau también se refiere, en algunos fragmentos de su obra, a la existencia de un "movimiento doble", que "va del representado al representante" y "del representante al representado" (Laclau, 2003b, p. 213). En "La razón populista" señala que

"La representación constituye un proceso en dos sentidos: un movimiento desde el representado hacia el representante y un movimiento correlativo del representante hacia el representado" (Laclau, 2005a, p. 200). 
De manera tal que el ejercicio de la representación posee dos dimensiones inherentes que interactúan en la dinámica política:

a. Desde el lado descendente del representante hacia lo representado, la representación política constituye un medio de homogeneización, que unifica (re-presenta) imaginariamente a la sociedad, conformando, de forma contingente, precaria y parcial, determinado orden comunitario. A su vez, como las interpelaciones y las decisiones públicas del representante siempre incorporan un "plus" en el proceso de representación política, toda identidad es capaz de ser reformulada y redefinida históricamente, sin que los liderazgos políticos dejen de ser, necesariamente, representativos.

b. Desde el lado ascendente, el representante político debe procurar ser representativo, es decir, debe efectivamente representar a sus representados, teniendo en cuenta cierta voluntad política (no preconstituida) del pueblo, priorizando la articulación de las demandas sociales insatisfechas de los de abajo.

En el momento de examinar el plano óntico-existencial, Laclau señala que el representante "no puede volverse totalmente autónomo de ellos" [los representados]. De manera tal que, si por un lado, todo representante político construye un lazo de representación, al "hacer presente algo que se encuentra ausente", por el otro debe "efectivamente representarlos" (Laclau, 2005a, pp. 204-205 y p. 213). Ello le permite marcar una diferencia frente al modelo de representación absoluta hobbesiano.

En la recopilación de su último trabajo, Laclau retorna a este problema central de la praxis política, sosteniendo que el líder populista cumple un doble rol de representación "ascendente" ("vertical") y "descendente" ("horizontal"). En ese sentido, nos advierte sobre el riesgo de una excesiva autonomía del líder sobre los representados y destaca la importancia de la dimensión participativa, junto a la representativa (Laclau, 2014, pp. 19-20).

Ahora bien, más allá de estos aportes, Laclau en ningún momento profundizó en los problemas ónticos que se producen entre las formas de representación vertical y descendente y las formas de participación popular del demos, ni reflexionó críticamente sobre la tensión que existe entre las decisiones personalistas del líder y los aspectos igualitaristas, colectivos y horizontales de la democracia popular. Tampoco exa- minó en profundidad los vínculos y tensiones históricas entre el papel decisionista del líder populista y las formas pluralistas e institucionales de las democracias representativas actuales. En su última etapa, de hecho, el teórico argentino realizó un triple relegamiento sintomático de los aspectos participativos, pluralistas e institucionales que había conceptualizado en sus textos de mediados los años ' 80 y comienzos de los '90, con su teoría de la "democracia radical y plural" (Fair, 2015). Estos problemas teóricos, como veremos a continuación, contienen importantes implicancias normativas para la praxis política en las democracias contemporáneas.

\section{LA DISCUSIÓN SOBRE EL PAPEL DE LOS LIDERAZGOS POLÍTICOS Y LA TENSIÓN CON LAS INSTITUCIONES REPRESENTATIVO-LIBERALES EN LAS DEMOCRACIAS CONTEMPORÁNEAS}

A diferencia de lo que plantean los enfoques neoinstitucionalistas de la Ciencia Política, que idealizan el modo de funcionamiento del parlamentarismo europeo, América Latina cuenta con regímenes presidencialistas en los que la representación mediante liderazgos asume un papel privilegiado. En el marco de su legitimidad de base democrático-popular, la fuerte personalización del vínculo político y el uso de los poderes de prerrogativa institucionalmente delimitados, la figura del Presidente adquiere una autoridad política central, más allá de algunas excepciones en donde los partidos políticos conservan mayor fuerza (Chile, Costa Rica, Uruguay). De este modo, no sólo los partidos políticos, sino también los liderazgos, pueden ser (e históricamente han sido) representativos y democráticos.

El problema principal radica en que la Ciencia Política predominante sólo asume como válida una concepción de la democracia de estirpe liberal (con frecuencia, combinada con elementos afines de las teorías republicanas), en el que las decisiones tomadas de forma individual por el Presidente, incluyendo el uso de mecanismos formales como los decretos y vetos delimitados en la Constitución, necesariamente atentan contra la democracia, ya que implican la toma de decisiones de forma individual y no colectiva. De este modo, el poder se concentra en las decisiones personalistas del líder político, evitando la deliberación pública a nivel institucional y el respeto a la soberanía popular condensada en el sistema legal y en su representante primordial, el Parlamento. Aunque hemos visto que existen perspectivas alternativas, de orientación schmittiana, que sostienen que las decisiones del líder son capaces de reconstruir los vínculos representativos, y la experiencia histórica 
demuestra en América Latina la existencia de fuertes y duraderos lazos políticos entre la ciudadanía y los liderazgos representativos, se mantiene la influencia de la concepción poliárquica de la democracia, lo que conduce a criticar el impacto del estilo de liderazgo personalista sobre las instituciones representativas de la democracia liberal ${ }^{13}$.

Desde el posfundacionalismo, Laclau (2005a) realizó una doble innovación conceptual, al definir al populismo como una lógica político-discursiva y al sostener que la figura del líder populista puede ser democrático y representativo. Ello lo condujo a cierta revalorización de la dimensión democrático-popular de los populismos y de los liderazgos populistas latinoamericanos, y a relegar la importancia de los aspectos institucionales y pluralistas.

Antes de seguir avanzando es importante tener en cuenta que, en contraste con lo que plantean los ideólogos de la "democracia liberal", la democracia y el liberalismo constituyen tradiciones teórica e históricamente divergentes. Si bien desde finales del siglo XIX han tendido a mixturarse, ambas presuponen principios y valores diferentes (Macpherson, 1982; Bobbio, 1993 y 2012; Mouffe, 1999 y 2007). Como señala Nun (2001), la democracia clásica asume la tesis rousseauniana del "gobierno del pueblo" (demos=pueblo y kratia=gobierno), en base a un ideal de "auto-gobierno" comunitario, centrado en la participación social universal y horizontal y la igualdad sustantiva (económica y social). El liberalismo, en cambio, entiende a la democracia como "gobierno de los políticos", a partir de las decisiones tomadas por una pequeña elite política que debe respetar, promover y garantizar los derechos y libertades civiles, políticas y económicas de los individuos frente al poder arbitrario del Estado (básicamente, libertad de prensa, de expresión, de asociación, de culto, de cátedra y de comercio, derecho a una vida privada y respeto a la vida y a la propiedad privada). Mientras que los ejes centrales de la concepción clásica de la democracia son el autogobierno del demos, la igualdad social y la participación colectiva y popular, el liberalismo se centra en el resguardo de las libertades de los individuos (en un sentido negativo) y en la representación política mediante el correcto funcionamiento de los mecanismos institucionales del Estado de Derecho, asumiendo a nivel económico la defensa de la propiedad privada y el libre comercio ${ }^{14}$.

Ahora bien, si la teoría de la democracia representativa-liberal relega la defensa de los derechos económicos y sociales de las mayorías populares y los aspectos participativos y horizontales del demos (en particular, los no institucionalizados), sabemos, desde las reflexiones de Rousseau (1995), que en las democracias modernas el demos no puede auto-gobernarse plenamente. En ese sentido, todas las teorías modernas realistas de la democracia han asumido la inevitabilidad de ciertas formas de representación política de lo social.

Sin embargo, vimos que desde la Ciencia Política neo-institucionalista, con su matriz política liberalrepublicana, la representación política se reduce a los canales institucionales y al papel central del Parlamento como órgano representativo de la soberanía popular. En esta línea, se ha acusado a la teoría del populismo de Laclau de asumir una concepción decisionista, autoritaria y anti-institucional, contraria a las democracias "poliárquicas". Aunque es cierto que la teoría de la hegemonía de Laclau no problematiza, sintomáticamente, el papel del Parlamento y de los partidos políticos y la importancia de respetar la división y el equilibrio de poderes, y que la teoría más reciente del populismo profundiza el relegamiento de los aspectos institucionales y pluralistas, no por ello ignora completamente estos factores. A continuación, examinaremos con más detalle estas cuestiones centrales para la discusión teórica y práctica de la política actual, analizando tanto los aspectos ontológico-conceptuales, como los óntico-empíricos y los anudamientos entre ambos planos.

\section{LA CUESTIÓN DE LA INSTITUCIONALIDAD EN LA TEORÍA DEL POPULISMO DE LACLAU}

La teoría posfundacional del populismo de Laclau prioriza la construcción de una ontología políticodiscursiva, que define al populismo como una forma de construir las identidades políticas y plantea una contraposición entre la lógica "populista" y la lógica "institucionalista". Desde el plano normativo, Laclau deja de lado las contribuciones teórico-políticas para la construcción de una "estrategia socialista" y para el desarrollo de una democracia "radical y plural", presente en sus textos de los años ' 80 y comienzos de los '90, asumiendo una concepción normativa débil (Fair, 2015).

En relación a la cuestión de los liderazgos políticos y la institucionalidad, lo primero que debemos señalar es que, desde la concepción constructivista social de Laclau, la distinción de categorías analíticas constituye una diferenciación político-discursiva y no un logicismo (ya sea desde una lógica realista aristotélica, un subjetivismo cartesiano, un logicismo idealista hegeliano o un positivismo lógico). Ello significa que toda lógica responde a una construcción discursiva, 
que se estructura social e históricamente desde el orden significante. Al ser una construcción discursiva e histórica, carece de esencias y fundamentos ahistóricos y universalistas, de manera tal que toda lógica implica una construcción particular, relativa, precaria y parcial de la realidad social. En razón de estas características, desde la perspectiva posfundacional de Laclau las disyunciones estrictas y tajantes de las lógicas sociales se disuelven en la contingencia del análisis histórico-político.

Al desplazarse al análisis político, en "La razón populista" el propio Laclau pone en evidencia que no existe una distinción estricta y tajante entre las lógicas políticas. En este sentido, destaca la existencia de una "tensión permanente" entre la "lógica de la equivalencia" y la "lógica de la diferencia" (Laclau, 2005a, pp. 94, p. 106, p. 153 y p. 249), que "se necesitan una a la otra como condiciones necesarias para la construcción de lo social". De esta manera, "lo social no es otra cosa que el locus de esta tensión insoluble" ( $p$. 106). En efecto, "la equivalencia no intenta eliminar las diferencias". Por lo tanto, "la diferencia continúa operando dentro de la equivalencia" (p. 105). Ello conduce a Laclau reconocer que existen "diferentes grados de universalidad" de lo social ${ }^{15}$ (p. 247). A partir del reconocimiento de esta tensión constitutiva, define al populismo como una "lógica política" que, con independencia del contenido, implica una "articulación variable de la equivalencia y la diferencia" ( $p$. 150). Sin embargo, la proporción entre la equivalencia y la diferencia se inscribe en un "espacio de variaciones" muy amplio en la dinámica política:

Si la lógica equivalencial no disuelve las diferencias, sino que las inscribe dentro de sí, y si el peso relativo de las dos lógicas depende en gran medida de la autonomía de aquello que se inscribe respecto a la hegemonía ejercida por la superficie de inscripción, el espacio de variación abierto por el doble reflejo es, de hecho muy grande (Laclau, 2005a, p. 155).

Según el pensador argentino, para distinguir a las identidades populistas se requiere del análisis del "predominio" de "uno de los dos polos" (diferencial o equivalencial) (p. 249). En ese marco, si el populismo se caracteriza por priorizar una articulación equivalencial de las "demandas sociales insatisfechas" de "los de abajo", toda identidad política es siempre, "hasta cierto punto", populista" (p. 195).

Ahora bien, ¿cómo es posible distinguir analíticamente a los discursos populistas de los institucionalistas? Según Laclau, la distinción responde al grado de "extensión" que articula a las "cadenas equivalenciales". Ello implica diferenciar entre discursos "más institucionalistas" (en los que predomina la "lógica de la diferencia") y aquellos más "populistas", en los que predomina la "ruptura" y "tienden a dividir lo social" en dos partes antagónicas:

No existe ninguna intervención política que no sea hasta cierto punto populista. Sin embargo, esto no significa que todos los proyectos políticos sean igualmente populistas, eso depende de la extensión de la cadena equivalencial que unifica las demandas sociales. En tipos de discursos más institucionalistas (dominados por la lógica de la diferencia), esa cadena se reduce al mínimo, mientras que su extensión será máxima en los discursos de ruptura, que tienden a dividir lo social en dos campos (Laclau, 2005a, p. 195).

Como señala en un texto del 2005 (reeditado en español en el 2009), que realiza una síntesis de su teoría del populismo, para poder analizar estas tensiones entre la lógica diferencial y equivalencial desde la dinámica política, se debe considerar la mayor o menor extensión de la lógica de la equivalencia, por sobre la lógica de la diferencia. De modo tal que, si se pretende analizar a los fenómenos políticos desde las experiencias históricas, la estrategia a seguir consiste en observar el predominio contextual de alguna de estas dos lógicas, antes que fijar taxativamente la contraposición estricta y tajante populismo Vs. institucionalismo:

Preguntarnos si un movimiento es o no populista es, en realidad, comenzar con la pregunta errónea. Lo que deberíamos preguntarnos es, en cambio, lo siguiente: ¿hasta qué punto es populista un movimiento? Como sabemos, esta pregunta es idéntica a esta otra, ¿̇hasta qué punto la lógica de la equivalencia domina su discurso? (Laclau, 2009, pp. 66-67).

Este tipo de análisis permite identificar, mediante la incorporación de un "continuum" histórico, "hasta qué punto" un movimiento se acerca tendencialmente a la diferenciación extrema o a la división pura del espacio social. Sin embargo, ambos "extremos" son, por definición, "imposibles". En el primer caso límite, ello implicaría un individualismo tan extremo que no existiría ningún tipo de articulación social equivalencial ni de frontera política y la misma lucha política perdería todo sentido. En el segundo caso límite, se presentaría el extremo opuesto de la eliminación de todo carácter diferencial del significante, lo que supondría subsumir el concepto de equivalencia en la plena identidad de lo social. En palabras de Laclau: 
Hemos presentado las prácticas políticas como operando en diversos puntos de un continuum cuyos dos extremos serían, por reducción al absurdo, un discurso institucionalista dominado por una lógica pura de la diferencia y un discurso populista, en el cual la lógica de la equivalencia opera de modo irrestricto. Estos dos extremos son, en realidad, imposibles: la diferencia pura significa una sociedad dominada a tal punto por la administración y por la individualización de las demandas sociales, que ninguna lucha en torno a las fronteras internas, es decir, ninguna política, sería posible; y la equivalencia pura implicaría tal disolución de los vínculos sociales, que la propia noción de demanda social perdería todo sentido (Laclau, 2009, pp. 66-67).

Como se puede apreciar, Laclau afirma que los "extremos" populistas e institucionalistas son un "absurdo", ya que siempre existen combinaciones histórico-políticas que rompen con la "lógica pura". En ese marco, teniendo en cuenta, a partir del ejemplo del peronismo clásico, que "la ruptura populista se vuelve progresivamente más institucionalizada, de manera tal que la lógica diferencial comienza a prevalecer", Laclau destaca que entre ambas lógicas se presenta siempre una "dialéctica compleja" y un "compromiso inestable" y que cada situación histórica debe examinar cómo se manifiesta esta tensión:

La equivalencia es, claramente, una forma de articular diferencias. Hay, por tanto, entre la equivalencia y la diferencia, una dialéctica compleja, un compromiso inestable. Existe una variedad de situaciones históricas que presuponen la presencia de ambas, pero al mismo tiempo, su tensión (Laclau, 2009, p. 67).

Este reconocimiento de las "variaciones históricas" que "presuponen" ambas lógicas de un modo "complejo", lo lleva a concluir que la diferencia se reduce a una cuestión de "grados" de articulación y que, por consiguiente, todo movimiento político presupone al menos cierto "grado de populismo" (y cierto grado de institucionalismo):

Un discurso va a ser más o menos populista dependiendo del grado en que sus contenidos son articulados por lógicas equivalenciales. Esto significa que ningún tipo de movimiento político va a estar completamente exento de populismo (Laclau, 2009, p. 68).

En este fragmento queda en claro que el populismo se encuentra presente en toda construcción identitaria, y que su caracterización depende del análisis de los grados de articulación de las cadenas equivalenciales a nivel extensivo. De manera tal que, al analizar fenómenos históricos concretos, ningún movimiento estará "completamente exento de populismo", e incluso podemos afirmar, siguiendo este planteo, que ninguna formación estará completamente exenta de institucionalismo. El modo de resolver esta tensión consiste en especificar contextualmente el grado de articulación y predominio de la lógica de la equivalencia en relación a la lógica de la diferencia, en el momento en que la equivalencia nunca puede alcanzar una identidad plena sin auto-disolverse ${ }^{16}$.

En un trabajo posterior, escrito en el año 2006, Laclau (2006a, p. 56) vuelve a decirnos que "no hay política que no tenga algún matiz populista" y que se trata, en ese sentido, de una cuestión de grados y proporciones de prevalencia de las lógicas equivalenciales o diferenciales. De manera tal que, en los fenómenos políticos, se presentan combinaciones en diversas proporciones. En sus palabras:

Como puede verse, el populismo es una cuestión de grado, de la proporción en que las lógicas equivalenciales prevalecen sobre las diferenciales. Pero la prevalencia de una u otra nunca puede ser total. Nunca habrá una lógica popular dicotómica que disuelva en un ciento por ciento el aparato institucional de la sociedad. Y tampoco habrá un sistema institucional que funcione como un mecanismo de relojería tan perfecto que no dé lugar a antagonismos y a relaciones equivalenciales entre demandas heterogéneas (Laclau, 2006a, p. 58).

Según Laclau (2006a), "la prevalencia exclusiva de esta lógica institucional conduciría a la muerte de la política y a su reemplazo por la mera administración". Debido a que los antagonismos son constitutivos de las identidades políticas y ninguna formación puede eliminar plenamente la diferencialidad, entonces el analista político debe hacer hincapié en los "grados" o "proporciones" en los que la lógica equivalencial "prevalece" (o no) sobre la articulación "diferencial".

En "La razón populista" Laclau plantea esta tesis de la "tensión" existente entre la lógica de la diferencia y la lógica de la equivalencia, empleando una metáfora de matriz lacaniana. En ese sentido, para explicar el absurdo de un discurso puramente institucionalista, sostiene que un discurso que no fija sentidos es un discurso "psicótico". En términos políticos, el ejemplo extremo que plantea como un discurso de "absorción diferencial", en el cual se absorben las demandas "cada una de manera separada de las otras" (Laclau, 2005a, p. 98), es la mítica propuesta de Saint Simón de realizar una administración gestionaria y tecnocrática de lo social, para pasar "del gobierno de los hombres a 
la administración de las cosas" (Laclau, 2005a, p. 279; Laclau, 2008, p. 130). Sin embargo, este modo de construir las identidades basado en el ideal de la "administración pura" (Laclau, 2005a, p. 195), en el que se pretende instituir un "centro administrativo neutral, capaz de tratar las cuestiones sociales de una manera no política" (Laclau, 2003b, pp. 199-200), no es más que una utopía imposible, ya que olvida las luchas de poder y antagonismos constitutivos de todo orden social.

De la misma manera, pero en un sentido inverso que cuestiona a las visiones del Pueblo-Uno, una "equivalencia que fuera total dejaría de ser equivalencia, para convertirse en mera identidad". En esas circunstancias, "ya no habría una cadena, sino una masa homogénea, indiferenciada" (Laclau, 2005a, p. 249). Laclau reconoce, en ese sentido, que, así como no existe un orden social puramente gestionario, "nunca habrá una lógica popular dicotómica que disuelva en un ciento por ciento el aparato institucional de la sociedad"17 (Laclau, 2006a, p. 58).

En otras palabras, suponer que pueda existir un discurso puramente equivalencial, sin ningún elemento institucional, implicaría eliminar el propio carácter diferencial del significante o, en los términos políticos, su inherente dimensión de particularidad, para alcanzar la plena universalidad. De esta manera, ya no habría una lógica equivalencial ( $\equiv)$, sino la plena presencia (=), esto es, la identidad transparente que proponen los regímenes totalitarios y su intento de construir el Pueblo-Uno. Como se puede apreciar, ello supondría el fin de la práctica hegemónica y el retorno a un nuevo fundamentalismo, en tanto el elemento de particularidad y diferencialidad intrínseca de la forma de universalidad de toda operación hegemónica se vería eliminado ${ }^{18}$.

\subsection{El análisis de Laclau de los procesos histórico- políticos y las mixturas ónticas entre populismo e institucionalismo}

Ahora bien, ¿qué ocurre cuando Laclau analiza procesos políticos contemporáneos concretos, desplazándose al plano óntico-empírico? Hemos observado que el pensador argentino no plantea la irreductibilidad entre la lógica populista e institucionalista, sino la existencia de una interpenetración compleja, derivada del análisis de la proporción entre la lógica de la equivalencia y la lógica de la diferencia. En los (escasos) momentos en los que Laclau analiza la dinámica política concreta, se hace presente esta combinación entre el populismo y el institucionalismo, desde un abordaje en base a gradientes.
Así, en un trabajo del 2006, en el que analiza las características que asumen los regímenes políticos de los países de "centroizquierda" de nuestra región, Laclau distingue entre aquellas experiencias históricas en las que prevalece la dimensión institucionalista y se presentan "pocos elementos populistas", y aquellas otras en las que predomina la ruptura populista, para luego incluir los casos "intermedios". En palabras del teórico argentino:

En los casos de Chile y de Uruguay, la dimensión institucionalista ha predominado sobre el momento de ruptura en la transición de la dictadura a la democracia, por lo que pocos elementos populistas pueden encontrarse en estas experiencias; en tanto que en el caso venezolano el momento de ruptura es decisivo. Argentina y Brasil están en una posición intermedia (Laclau, 2006a, p. 60).

Como se puede apreciar, al desplazarse al plano óntico Laclau parte desde un análisis comparado de las experiencias políticas. A partir de allí, identifica tres niveles diferenciales. Por un lado, las experiencias contemporáneas en las que "predomina" la "dimensión institucionalista", como los casos de Chile y Uruguay. En segundo término, aquellos países, como la Venezuela de Chávez, en los que el momento de "ruptura" ha sido "decisivo". Finalmente, los ejemplos de la Argentina con los Kirchner y de Brasil con "Lula" Da Silva (por entonces Presidente de ese país), que presentan una "posición intermedia" entre ambos extremos. Aunque Laclau no profundiza en las estrategias metodológicas para distinguir de forma rigurosa estas experiencias políticas, su esquema abre la posibilidad para elaborar un análisis político en perspectiva comparada de las identidades "realmente existentes". Ello habilita al análisis de regímenes políticos híbridos que presentan diferentes grados de articulación de la cadena equivalencial.

Pero además, en un fragmento de "La razón populista" Laclau incorpora un argumento normativo para justificar la relevancia política de los aspectos institucionales. Así, refiere al liderazgo de Juan Perón en su regreso a la Argentina de 1973 como un ejemplo de una "situación extrema en la cual el amor por el padre es el único lazo entre los hermanos". Según el pensador argentino, "la consecuencia política es que la unidad de un pueblo constituido de esta manera es extremadamente frágil", ya que "el potencial antagonismo entre demandas contradictorias puede estallar en cualquier momento". Ello lo lleva a concluir que: 
"un amor por el líder que no cristaliza en ninguna forma de regularidad institucional, sólo puede resultar en identidades populares efímeras" (Laclau, 2005a, p. 270).

En otras palabras, las formas de "regularidad institucional" contribuyen a reforzar y consolidar la fuerza política de los liderazgos populistas.

\subsection{La cuestión del pluralismo social en la teoría del populismo de Laclau}

Hemos visto la tensión entre la lógica populista y la lógica institucionalista y sus mixturas ónticas. Sin embargo, podemos identificar un segundo eje específico de la controversia, que se vincula a la tensión que existe entre la teoría del populismo y la defensa del pluralismo político. A partir de la publicación de "La razón populista", Laclau abandona la conceptualización de la teoría de la democracia "radical y plural", que promovía la aceptación de las diferencias como constitutivas y el reconocimiento de las particularidades de los nuevos movimientos sociales (feministas, gays, anti-racistas, ecologistas, en defensa de los Derechos Humanos, etc.) (Laclau y Mouffe, 1987). De este modo, en esta última etapa de su obra Laclau deja de lado sus iniciales aportes lefortiano-tocquevillianos referidos a la defensa de la "revolución democrática" y a la dimensión "plural" de la democracia, vinculados al reconocimiento de las diferencias y particularidades sociales como aspectos valiosos.

Ahora bien, estos problemas conceptuales y normativos no implican que la teoría de la hegemonía de Laclau, y en particular la teoría del populismo, conduzcan necesariamente a un esquema anti-pluralista. Comenzando por el análisis del plano ontológico, debemos recordar que para Laclau la hegemonía supone una forma de construcción de las identidades políticas que mantiene siempre presente la dimensión de contingencia, precariedad e historicidad constitutivas de las identidades y del propio orden social. Ello supone la necesidad de reconocer la dimensión particular y parcial de toda forma de universalización de lo social. Si bien es cierto que en su última etapa Laclau no es tan explícito en este carácter particular de toda hegemonía, abandonando la teorización del aspecto "plural" de la "democracia radical", continúa reconociendo que toda hegemonía constituye un desplazamiento particular-universal que, necesariamente, se encuentra penetrado por la presencia de una "plenitud comunitaria ausente" (Laclau, 2005a, p. 143). En sus palabras:
Existe la posibilidad de que una diferencia, sin dejar de ser particular, asuma la representación de una totalidad inconmensurable. De esta manera, su cuerpo está dividido entre la particularidad que ella aún es y la significación más universal de la que es portadora. Esta operación por la que una particularidad asume una significación universal inconmensurable consigo misma es lo que denominamos hegemonía (Laclau, 2005a, p. 95).

En el mismo sentido, Laclau reconoce la distinción de "gradaciones" que existe en las formas históricas que asumen las operaciones hegemónicas, de manera tal que:

Entre la encarnación total y la vacuidad total existe una gradación de situaciones que involucran encarnaciones parciales. $Y$ éstas son, precisamente, las formas que toman las prácticas hegemónicas (Laclau, 2005a, p. 210).

Este reconocimiento del desplazamiento retórico de toda operación hegemónica lo lleva a destacar la imposibilidad constitutiva de una equivalencia "total", ya que ello significaría eliminar el carácter "diferencial" de toda equivalencia, para convertirse en una "mera identidad". Así:

Una equivalencia que fuera total dejaría de ser equivalencia para convertirse en mera identidad: ya no habría una cadena, sino una masa homogénea indiferenciada (Laclau, 2005a, p. 249).

El resultado de una construcción de este tipo implicaría acceder a una "masa homogénea indiferenciada", el Pueblo-Uno, lo que eliminaría la validez del propio concepto de hegemonía.

\subsection{Los vínculos ónticos entre el populismo y el li- beralismo político desde la teoría del populismo de Laclau}

En el marco del estiramiento conceptual del populismo, que relega las diferencias que existen entre un orden autoritario o autocrático (iliberal) y un orden dictatorial o totalitario (antiliberal), en su última etapa Laclau subordina los vínculos y afinidades con el liberalismo político, lo que se traduce en una escasa conceptualización y defensa de los aspectos institucionales y pluralistas. Sin embargo, en algunos pasajes de "La razón populista" el propio Laclau recupera algunos elementos de dicha tradición cultural, al enfatizar en la importancia que adquiere la defensa de las libertades civiles y los Derechos Humanos. El pensador argentino señala que estos valores no son necesariamente excluyentes con la democracia popular 
en el mundo actual. Así, en un poco conocido y citado fragmento de "La razón populista", Laclau afirma que estos principios liberales pueden complementarse con la tradición clásica de la democracia y con la defensa de las "demandas populares". En sus palabras:

Es un error pensar que la tradición democrática, con su defensa de la soberanía del pueblo, excluye como cuestión de principio las demandas liberales. Eso sólo podría significar que la identidad del pueblo está definitivamente fijada. Si, por el contrario, la identidad del pueblo sólo se establece a través de cadenas equivalenciales cambiantes, no hay razón para pensar que un populismo que incluye los Derechos Humanos como uno de sus componentes es excluido a priori. En algunos momentos, como ocurre frecuentemente en la actualidad en la escena internacional, la defensa de los Derechos Humanos y de las libertades civiles pueden convertirse en las demandas populares más apremiantes (Laclau, 2005a, p. 216).

De un modo similar, en su último libro, que recoge una serie de escritos previos, Laclau reconoce la existencia de diferentes grados de pluralismo en los fenómenos histórico-políticos. En este sentido, distingue dos concepciones en pugna sobre la democracia. La primera de ellas, vinculada a la concepción "jacobina", la denomina democracia "como intento de constituir el pueblo uno". La segunda, asociada a los nuevos movimientos sociales pluralistas (liberales), corresponde a la democracia como "respeto por la diferencia". Como ejemplo de la democracia como "Pueblo uno", Laclau menciona al Terror de Robespierre y a la dictadura de Pol Pot, mientras que en la concepción de la democracia como "respeto por la diferencia", menciona como ejemplo a los nuevos movimientos sociales. A partir de la distinción de estas dos concepciones, el pensador argentino señala que "dentro de esta polarización básica encontramos, desde luego, todo tipo de posibles combinaciones intermedias" (Laclau, 2014, pp. 124-125). De esta manera, habilita a analizar las experiencias intermedias entre ambos extremos.

Estos valiosos aportes vinculados a ejemplos históricos disuelven definitivamente toda disyunción estricta y tajante entre el populismo y el institucionalismo y entre la tradición democrática y la liberal, permitiendo combinarlos entre sí en la dinámica política. Sin embargo, al mismo tiempo debemos reconocer que tienen argumentos suficientes los críticos que han destacado el debilitamiento y subordinación de la teoría del populismo de los aspectos pluralistas y sus riesgos para una praxis democrática. El peligro de un populismo que devenga esencialista y que busque eliminar el aspecto de particularidad inherente a la operación hegemónica para construir un orden autocrático, dictatorial o totalitario, permanece como una posibilidad ${ }^{19}$.

Entendemos que resulta primordial tener en cuenta los problemas de esta subteorización de los aspectos institucionales y pluralistas por parte de la teoría del populismo, sobre todo para analizar la importancia que adquieren los mecanismos de mediación institucional y el respeto de las diferencias para consolidar el vínculo de representación política en las democracias actuales. En el próximo apartado destacaremos algunos aportes recientes en esta línea desde el campo posfundacional.

\section{CONTRIBUCIONES RECIENTES DESDE LA TEORÍA POLÍTICA POSFUNDACIONAL AL DEBATE SOBRE LA REPRESENTACIÓN POLIITICA MEDIANTE LIDERAZGOS Y LA CUESTIÓN INSTITUCIONAL}

El problema de la imprecisión conceptual, el énfasis en el plano ontológico, la escasa sistematicidad teórica y la ausencia de referencias empíricas y operativas de la teoría del populismo de Laclau, ha generado una multiplicidad de críticas desde el campo posfundacional latinoamericano. Algunos analizaron los vínculos entre los déficits teóricos y sus potenciales derivaciones ónticas. En este sentido, Ípola (2009) planteó los déficits de la teoría del populismo de Laclau en relación a la tradición liberal-democrática y el peligro que este déficit teórico se traduzca en un antipluralismo en la práctica real. Arditi (2010) se refirió el problema de la autonomía de los representados frente al líder político.

Otros autores aportaron recursos para sistematizar y operacionalizar la teoría del populismo (Barros, 2006; Groppo, 2011). En algunos casos, se brindaron herramientas operativas para caracterizar a las identidades populistas y examinar la relación tensional entre el populismo y la cuestión institucional, desde un análisis en base a gradientes. En esta línea, Aboy Carlés distinguió entre tres tipos de identidades populares, que definió como "parciales", "totales" y con "pretensión hegemónica". Mientras que las identidades "totales" realizan una "reducción violenta de la plebs en populus" y promueven formas "segregativas", en las identidades "parciales", en cambio, "no hay conversión de la plebs en populus". A su vez, entre las identidades con "pretensión hegemónica" se puede identificar, en un "rango extremadamente variado", formas de respeto al "plu- 
ralismo" y de "tolerancia", lo que permite distinguir entre experiencias políticas con mayor o menor respeto al pluralismo. Las identidades populistas (como el caso del peronismo), sin embargo, no alcanzan el extremo anti-liberal de las identidades "totales", en tanto en ningún momento rompieron plenamente con el "marco de competencia plural" (Aboy Carlés, 2013, pp. 28-38).

Esta conceptualización incorpora dos contribuciones clave para el análisis sociopolítico. En primer lugar, permite repensar los vínculos, tensiones y mixturas ónticas entre las tradiciones democráticas y liberales desde el análisis de las identidades políticas contemporáneas, frente a los estudios que suelen presentar a estas tradiciones como antagónicas y antitéticas. En segundo término, siguiendo la propuesta de Laclau de analizar el "predominio" de "uno de los dos polos" (diferencial o equivalencial) en la dinámica política (Laclau, 2005a, p. 249), permite incorporar un análisis en base a gradientes de estructuración de las identidades políticas, a partir de su reconocimiento óntico de la dimensión plural.

Balsa, por su parte, distinguió entre la lógica "institucionalista" y la lógica "administrativista", e indicó que el populismo como lógica de construcción política no es antagónico al "institucionalismo", sino al "administrativismo" (Balsa, 2013). En otras palabras, las lógicas contrapuestas del populismo y el institucionalismo deberían reconceptualizarse como populismo versus "administrativismo", en el momento en que el populismo en el poder necesariamente presenta cierta articulación con lo institucional (en particular, desde las formas de burocracia estatal). En sus palabras:

Es muy difícil pensar lo institucional (en tanto canalización de las demandas a través de la burocracia estatal) como una lógica diferenciada u opuesta al populismo, ya que de ese modo el populismo quedaría circunscripto a una etapa temporal previa al acceso al poder estatal. En cambio, lo opuesto a la lógica populista es una lógica administrativista. Es decir, el ideal saint-simoniano (y popperiano) de la política reducida a la administración del bien común, a la elección de la mejor técnica ${ }^{20}$ (Balsa, 2013, pp. 19-20).

Esta distinción conceptual resulta central, ya que permite colocar el eje de antagonismo de las identidades populistas en las formas meramente "gestionarias" o "tecnocráticas" de gobierno de lo público, que rechazan la existencia de relaciones desiguales de poder en el seno de la sociedad y el reconocimien- to explícito del carácter antagónico de todo ordenamiento social. De hecho, en "La razón populista" el propio Laclau recupera esta distinción, al afirmar que la "construcción del pueblo" debe ser entendido como el "acto político par excellence", para luego definirlo "como oposición a la administración pura, dentro de un marco institucional estable" (Laclau, 2005a, p. 195).

Por último, diversos referentes destacaron la combinación entre elementos populistas e institucionalistas en las experiencias históricas del populismo latinoamericano. Como señala Aboy Carlés, las experiencias populistas clásicas han tenido una "gigantesca creación de instituciones" (Aboy Carlés, 2014, p. 43), construyendo todo un entramado institucional novedoso. El peronismo, por ejemplo, extendió el voto a las mujeres, garantizando el sufragio universal, y creó tribunales laborales capaces de hacer cumplir la institución de nuevos derechos del trabajo (Aboy Carlés, 2010, p. 25). En el mismo sentido, Groppo (2011) destacó la vasta red institucional que caracterizó tanto al peronismo clásico, como al varguismo en Brasil. El primero de ellos, a través de la creación de un marco legal de protección de los trabajadores, que se inició con el establecimiento del estatuto del peón rural y la creación del Departamento Nacional de Trabajo (en 1944), que regulaba la relación entre empleadores y empleados, y continuó con la creación del Sueldo Anual Complementario (SAC o aguinaldo) (1945), la reglamentación formal del trabajador rural asalariado (1946) y la creación del Consejo Nacional del Trabajo Rural (1948) ${ }^{21}$ (Groppo, 2011, p. 150 y ss.). El segundo, mediante la reforma constitucional de 1934, que dio rango constitucional al salario mínimo regional e institucionalizó una serie de beneficios, como vacaciones pagas y asistencia médica, la sanción de la Ley de Seguridad Nacional (1935), la ley de salario mínimo (1936), la ley de sindicalización (1939) y la llamada Consolidación de las Leyes Laborales, que institucionalizaron la regionalización de los salarios (1943) (Groppo, 2011, p. 262 y ss.). Quiroga también señala que las experiencias populistas históricas han sido impulsoras de un "amplio entramado institucional". El peronismo, por ejemplo, realizó una reforma constitucional en 1949, que incorporó vastos derechos sociales y laborales (aguinaldo, vacaciones pagas, indemnizaciones por despido, etc.). Además, reorganizó el Banco Central y realizó una serie de nacionalizaciones. En Bolivia, el MNR creó también un amplio entramado institucional, nacionalizando empresas de servicios, sancionando el sufragio universal y realizando una reforma agraria y educativa ${ }^{22}$ (Quiroga, 2014, pp. 383-384). 


\section{LOS PROBLEMAS CONCEPTUALES DE LA TEORÍA DEL POPULISMO: CONTRIBUCIONES PARA UNA MA- YOR SISTEMATICIDAD ANALÍTICA}

En “La razón populista” Laclau plantea al populismo como una forma de construir las identidades políticas. Dentro de los ejemplos históricos incluye a gobiernos totalitarios y fundamentalistas, como los de Stalin, Hitler o Mao y los "etnopopulismos" europeos, junto a otros casos que, más allá de sus notables diferencias de contenido, aceptaron el régimen democrático y las libertades civiles básicas y mantuvieron el desplazamiento particular-universal de la forma hegemónica, como los casos de Margaret Thatcher y Silvio Berlusconi y los populismos "estatistas" latinoamericanos de Perón, Vargas y el MNR en Bolivia. En trabajos posteriores Laclau se refiere, además, a los gobiernos de "centroizquierda" en Argentina y Venezuela, a partir de los liderazgos de Kirchner y Chávez (Laclau, 2006a). La consecuencia de este esquema formal es que se presenta un enorme "estiramiento conceptual" de los populismos, lo que exacerba al extremo la imprecisión semántica y reduce la capacidad explicativa de la especificidad de estos fenómenos ${ }^{23}$. No se distingue, por ejemplo, entre las pretensiones hegemónicas de los populismos latinoamericanos (como el peronismo o el chavismo) y el carácter totalizador y fundamentalista de los totalitarismos (como el nazismo), que pretenden encarnar la sustancia de lo social. Además, el énfasis general en el aspecto formal coloca en la misma bolsa a fenómenos políticos como el peronismo y el fascismo, lo que impide destacar sus notables diferencias. Se deja de lado, así, que los populismos clásicos latinoamericanos (Cárdenas, Perón, Vargas) presentaron una forma de construir hegemonía reñida con el respeto al pluralismo social, pero no antipluralista, y que crearon todo un cuerpo propio de instituciones. Los totalitarismos (nazismo, fascismo), en cambio, asumieron una lógica anti-pluralista y antiinstitucional, siguiendo un esquema de control dictatorial y total de la sociedad.

Al desplazarse al plano óntico, observamos que existe, efectivamente, un problema conceptual con los ejemplos históricos que incluye Laclau. Experiencias como el nazismo o el fascismo, antes que al posfundacionalismo de los populismos latinoamericanos, se asemejan en mayor medida a lo que Laclau definía en textos previos como una "ideología" (Laclau, 2004) y que Lefort caracteriza como "totalitarismos", en el sentido de una identidad que pretende la (imposible) clausura y transparencia de lo social. Si toda construcción hegemónica implica la persistencia de un residuo de particularidad y de desplazamiento metonímico, experiencias históricas como el nazismo y el socialismo soviético constituyeron totalitarismos que, por vías opuestas, pretendieron acceder a un universal pleno y trituraron el elemento particular, diferencial y contingente de lo social. Sólo en el primer caso podemos hablar de experiencias con pretensión hegemónica, mientras que en el segundo caso el deseo de construir la homogeneidad total dejó de ser una ficción simbólica o una metáfora del universal imposible, para edificar un orden que pretendió eliminar, tanto simbólica como físicamente, todo vestigio de diferencialidad, particularidad y contingencia de lo social ${ }^{24}$.

Como una respuesta a estos problemas de la teoría del populismo de Laclau, planteamos una doble operación analítica:

1. Distinguir conceptualmente entre los elementos institucionales, plurales y administrativos de la tradición liberal, que aparecen yuxtapuestos en el esquema laclauciano.

2. Distinguir conceptualmente entre las formas populistas (posfundacionales) y las formas ideológicas (fundacionales), teniendo en cuenta las diferencias de gradientes entre el autoritarismo, la dictadura y el totalitarismo.

\subsection{Distinguiendo entre los elementos instituciona- les, plurales y administrativos}

La primera operación analítica consiste en distinguir una serie de conceptos que aparecen superpuestos en la teoría del populismo bajo el nombre de "institucionalismo". Para ello, debemos diferenciar entre lo que constituye lo institucional, el pluralismo social y los aspectos administrativos, procedimentales y técnico-burocráticos.

Lo institucional: se vincula al entramado de reglas y normas instituidas y tipificadas, sea de modo formal o informal, que regulan los comportamientos y conductas y otorgan estabilidad y previsibilidad social.

El pluralismo: puede ser distinguido en social e institucional. El pluralismo social se vincula al respeto a la pluralidad de puntos de vista y a la aceptación o tolerancia de las diferencias sociales y culturales como legítimas. El pluralismo institucional se relaciona al respeto al Estado de derecho y a la división de poderes y funciones de la democracia republicana.

Lo burocrático o técnico-administrativo: corresponde a uno de los aspectos institucionales, vinculado a las formas tipificadas de gestión técnica y administrativa, tendientes a la organización y resolución de los problemas sociales y políticos. 
Los primeros dos aspectos se relacionan con elementos típicos de las tradiciones del liberalismo político y el republicanismo y han sido largamente destacados desde las concepciones predominantes de la Ciencia Política ${ }^{25}$. Mientras que las teorías del liberalismo político, más allá de sus divergencias, confluyen en la defensa de las libertades, derechos y garantías individuales desde una concepción negativa de la libertad, las visiones republicanas, más allá de sus divergencias, priorizan la división funcional de poderes y la igualdad ante la ley, además de oponerse a la corrupción, desde una concepción positiva de la libertad. La incorporación de estos aspectos implica considerar que existen determinados derechos y libertades individuales, garantizados por las instituciones públicas del Estado de Derecho, que protegen a los individuos y a las minorías culturales de las imposiciones arbitrarias de los gobiernos y de los deseos de las mayorías populares y que existen normas y leyes públicas que garantizan la universalidad de los derechos y la igualdad de todos los ciudadanos ante la ley y les otorgan estabilidad y perdurabilidad en el tiempo, bajo el sustento del poder coactivo del Estado ${ }^{26}$. En cuanto al eje de lo burocrático y administrativo, tal como ha sido destacado por Weber (1984), constituye la forma de organización y de dominación racional que predomina en los Estados Modernos, estando presente en diferentes regímenes de gobierno.

\subsection{Distinguiendo entre la lógica populista (posfun- dacional) y la lógica totalitaria (fundamentalista)}

La segunda operación consiste en distinguir entre la lógica populista y la totalitaria. Para ello, debemos tener en cuenta la diferencia de gradientes que existe entre el autoritarismo, la dictadura y el totalitarismo. Desde una concepción liberal y republicana de la democracia, se puede conceptualizar a los gobiernos que no respetan los aspectos pluralistas e institucionales de acuerdo al grado de respeto a estos componentes. Mientras que la lógica populista se caracteriza por tener una pretensión hegemónica que resguarda, si bien a regañadientes, las libertades y derechos individuales y los elementos básicos del Estado de Derecho, las dictaduras militares, y en particular los totalitarismos, eliminan estas libertades y derechos civiles y políticos y gobiernan sin respetar los mecanismos institucionales del Estado de Derecho. La Ciencia Política ha distinguido, en ese sentido, entre los gobiernos democráticos (en el sentido de "poliarquías") y los "autocráticos", y diferenciado, a su vez, entre los gobiernos "iliberales" y los anti-liberales ${ }^{27}$.
Retomando los conceptos laclausianos, el totalitarismo, como intento de alcanzar la transparencia y plenitud de lo social, no puede ser situado en la misma categoría que el populismo, en tanto el primero procura construir identidades totalizadoras que eliminan el desplazamiento particular-universal propio de la construcción hegemónica, con el objeto de edificar un universal puro. La hegemonía, en cambio, implica un desplazamiento metonímico de lo particular para asumir un "universalismo relativo" (Laclau, 1993, p. 229; 1996, p. 97) y "precario" (Laclau, 2008, p. 130), que nunca elimina el resto de particularidad. Se trata, en efecto, de un "movimiento hegemónico", en el que "el cuerpo de una particularidad asume la función de representación universal" (Laclau, 2003, p. 302). Retomando algunos trabajos de Laclau de los años '90 (reeditados en su último libro del 2014), proponemos emplear el nombre de "ideologías" para referirnos a los gobiernos que, en la práctica histórica, procuran encarnar el Pueblo-Uno como sustancia y totalidad, eliminando el desplazamiento hegemónico y, por lo tanto, el carácter contingente, precario y parcial de lo social ${ }^{28}$. De manera tal que debemos distinguir entre:

Populismo: constituye una forma de construir las identidades políticas y el orden social que se caracteriza por priorizar la articulación equivalencial de las demandas sociales y realizar una partición tendencial del espacio social en dos partes antagónicas (el pueblo contra el poder). Mantiene una pretensión hegemónica que no elimina el residuo de particularidad y diferencialidad. Al aceptar (en ocasiones, a regañadientes) la particularidad de la operación hegemónica, representa una forma posfundacional de construcción de las identidades y del orden social.

Ideología: constituye una forma fantasmática de construir las identidades políticas y el orden social que se caracteriza por pretender encarnar el fundamento de lo social como una universalidad plena y transparente, ya sea buscando eliminar verbal y físicamente las particularidades y diferencias constitutivas para acceder al Pueblo-Uno, o bien negando el carácter político (antagónico) de lo social. Al rechazar la legitimidad de las diferencias y particularidades, negar los antagonismos constitutivos y la contingencia de lo social, representa una forma fundamentalista e ilusoria de construcción de las identidades y del orden social.

En el momento en que un discurso populista abandona su componente de respeto básico a las particularidades y diferencias y se esencializa, pasa a convertirse en una ideología de la totalidad, disolviendo sus pretensiones hegemónicas. 
Esta distinción es importante, ya que permite una mayor precisión conceptual, distinguiendo a los gobiernos populistas (como por ejemplo el peronismo clásico) de los totalitarismos históricos (como el fascismo italiano), que en ocasiones han tendido a ser integrados en un mismo espacio por las perspectivas liberales. Además, abre la posibilidad de profundizar en la crítica normativa (política) a las ideologías totalitarias, destacando, junto a sus contenidos segregativos y socialmente excluyentes, de matriz biopolítica, su carácter de construcción meramente imaginaria (fantasmática, utópica, mítica) e imposible ${ }^{29}$.

\subsection{Cuatro lógicas de construcción las identidades políticas}

A partir de las distinciones que hemos propuesto, podemos identificar cuatro lógicas diferenciales de construir las identidades y el orden social, que se presentan como un continuum en la dinámica política:

a. Lógica populista: constituye una lógica posfundacional de construcción de las identidades políticas, que (a) prioriza la articulación equivalencial de las demandas sociales de las mayorías populares, (b) fomenta las formas de movilización social por afuera de los canales institucionales de la democracia representativa, (c) promueve la división tendencial del espacio social en dos partes antitéticas, explicitando los antagonismos sociales. (d) Mantiene un respeto a los aspectos institucionales y pluralistas básicos del régimen democrático de gobierno $y$, por lo tanto, el residuo de particularidad y la contingencia de lo social. (e) Presenta una pretensión hegemónica, manteniendo el desplazamiento particular-universal de la forma hegemónica.

b. Lógica institucionalista: constituye una lógica posfundacional de construcción de las identidades políticas que (a) prioriza la absorción diferencial de las demandas sociales, (b) fomenta las formas de gestión técnica y de participación social dentro de los canales institucionales de la democracia representativa, (c) no divide el espacio social en dos partes antitéticas, promoviendo las formas consensuales. (d) Privilegia el respeto a las formas de gestión y a los mecanismos institucionales y pluralistas del régimen democrático y, por lo tanto, la aceptación de las particularidades y la contingencia de lo social. (e) Presenta una pretensión hegemónica, manteniendo el desplazamiento metonímico de la forma hegemónica. c. Lógica totalitaria: constituye una lógica fundamentalista de construcción de las identidades políticas y el orden social que se caracteriza por destruir las particularidades y el respeto al pluralismo social e institucional, procurando eliminar la contingencia y diferencialidad constitutivas, para encarnar la ilusoria transparencia de lo social. No presenta una pretensión hegemónica, sino totalizante. Al pretender eliminar las diferencias constitutivas, representa una forma fantasmática (fantasiosa) e ilusoria de construir el orden social.

d. Lógica tecnocrática: constituye una lógica fundamentalista de construcción de las identidades políticas y el orden social que se caracteriza por extremar las formas de absorción diferencial de las demandas, los mecanismos de gestión técnica y los procedimientos burocráticos y formales, negando legitimidad a las formas de movilización y protesta social por afuera de los canales institucionales y la existencia de antagonismos sociales constitutivos. Al pretender eliminar los antagonismos inherentes para encarnar la transparencia de lo social, constituye una forma totalizante de construir las identidades. De este modo, representa una lógica fantasmática e ilusoria de construir el orden social.

En los fenómenos histórico-políticos, teniendo en cuenta los lineamientos teóricos destacados por Laclau, se suele presentar una combinación entre elementos populistas e institucionalistas. Los movimientos populistas, a su vez, presentan entre sí diferentes gradientes de respeto a los mecanismos de pluralismo social e institucional. Por ejemplo, el peronismo clásico presentó más tensiones con el respeto al pluralismo que el kirchnerismo. De manera tal que se puede distinguir un continuum, desde el análisis históricopolítico de las experiencias concretas.

Los últimos dos casos representan lógicas fantasmáticas e ilusorias de construir el orden social, cuyos ejemplos límite son la utopía de Saint Simon y de los tecnócratas neoliberales de construir un orden puramente gestionario y carente de relaciones desiguales de poder y formas de antagonismo social (lógica tecnocrática) y el intento de las ideologías totalitarias, como el fascismo italiano o alemán, de eliminar las diferencias y particularidades para acceder a una completa armonía y unidad del cuerpo social (lógica totalitaria). Ambas lógicas, por vías opuestas, remiten a construcciones imaginarias y fundamentalistas que pretenden eliminar lo político y la contingencia constitutiva de lo social. 


\section{LOS PROBLEMAS NORMATIVOS DE LA TEORÍA DEL POPULISMO DESDE LA DINÁMICA POLÍTICA}

Las imprecisiones conceptuales que hemos identificado en "La razón populista" se traducen en potenciales problemas a nivel óntico. Distinguimos dos problemas normativos desde la dinámica política. El primero de ellos, correspondiente a los déficits en la dimensión liberal-republicana, se vincula al eje Unidad - Diferencia. El segundo, correspondiente a los déficits en la dimensión popular-social, se relaciona al eje Representación - Participación. De estos problemas se derivan dos tensiones históricas:

a. La tensión existente entre las decisiones del líder político y la voluntad de las mayorías populares, por un lado, y el reconocimiento del pluralismo social, el respeto a las instituciones y a los procedimientos de la democracia representativa, por el otro (Eje Unidad - Diferencia).

b. La tensión existente entre las decisiones personalistas y verticales del líder político y las formas horizontales e igualitarias de participación popular del demos (Eje Representación - Participación).

A continuación, brindaremos algunas herramientas para responder a estas tensiones en las democracias representativas actuales.

\section{a) Contribuciones para fortalecer la dimensión plural y los aspectos institucionales en las democracias re- presentativas actuales}

La tensión entre las decisiones del líder y el respeto a las diferencias y particularidades constituye una de las discusiones centrales que atraviesan al liberalismo político y el republicanismo, perspectivas que lucharon históricamente contra las formas tiránicas de ejercicio del poder por parte de los Reyes y contra las formas de "tiranía de las mayorías" (Tocqueville, 1969), a partir de experiencias como el Terror de Robespierre y las dictaduras y totalitarismos del siglo XX. Hemos señalado previamente los déficits de la teoría del populismo de Laclau en este plano y aportado algunos recursos conceptuales para subsanarlo. En el siguiente apartado incorporaremos herramientas adicionales para responder a esta tensión desde el plano histórico-político, para lo cual retomaremos aportes de O’Donnell (2007).

Para alcanzar una democracia posfundacional consolidada, y evitar el peligro autocrático, dictatorial o totalitario, resulta fundamental integrar normativamente a las concepciones clásicas de la democracia, algunos aspectos centrales de las tradiciones del libe- ralismo radical y el republicanismo, vinculadas al eje pluralista de la democracia representativa. Partimos de la base que el poder decisorio no debe estar concentrado en determinadas figuras políticas que deciden de forma absolutamente autónoma, arbitraria e irrestricta, respetando al Estado de Derecho y los mecanismos de control institucional y promoviendo la crítica y el pluralismo social. Decimos, entonces, que para consolidar la democracia se debe:

1. Promover la difusión institucional del poder concentrado mediante el respeto a la división funcional de poderes y su control mutuo. Ello implica la necesidad de respetar y garantizar la relativa autonomía del Poder Legislativo y Judicial como entes que deben controlar, equilibrar y balancear el poder emanado de las directrices del Ejecutivo, a partir de los límites legalmente definidos.

2. Promover y garantizar el cumplimiento efectivo y universal de los derechos, garantías y libertades de los individuos sociales. Ello implica fomentar, respetar y garantizar desde el Estado: (a) el resultado de las elecciones periódicas libres y competitivas, (b) la máxima libertad posible de prensa, de expresión, de asociación, de participación y de culto, (c) el derecho a un juicio justo, (d) el libre ejercicio de la crítica pública radicalizada a los representantes e instituciones del poder político, garantizando la legitimidad y validez del conflicto, la aceptación de las disidencias y la máxima libertad posible para expresar la diversidad de ideas y valores políticos, sociales y culturales que forman parte de la condición humana, (e) el derecho a una vida privada.

3. Fomentar el cuidado y respeto irrestricto de los recursos públicos que forman parte del patrimonio común y nacional, castigando los actos ilícitos, de acuerdo al cumplimiento de los procedimientos formales.

4. Promover y garantizar el correcto funcionamiento de los mecanismos formales de rendición de cuentas ("accountability horizontal") y la máxima libertad, autonomía y transparencia de las agencias encargadas de ejercer la supervisión, el control, la rectificación y/o sanción de las decisiones, actos y/u omisiones presuntamente ilegales de otras instituciones del Estado y/o de los funcionarios de gobierno. En ese marco, se debe promover el acceso 
público a las fuentes de información del Estado, el funcionamiento autónomo de los mecanismos de control político e institucional, así como de las agencias, organismos y entes de regulación de la sociedad civil (auditorías, fiscalías, contralorías, etc.), contribuyendo a evitar las prácticas ultra-decisionistas, patrimonialistas, nepóticas y arbitrarias del gobierno y de los liderazgos políticos.

La institucionalización formal de estos derechos, libertades y garantías individuales, universalizados mediante un Estado que promulga y respalda el funcionamiento del sistema legal, provee de "un elemento básico de previsibilidad y estabilidad de las relaciones sociales" (O'Donnell, 2007, p. 164). En los términos del pensamiento posfundacional, estos aspectos institucionales contribuyen a sedimentar los discursos y prácticas discursivas y a reforzar su performatividad. De modo tal que consideramos que la figura del representante político, aun en sistemas hiper-presidencialistas y con fuertes tradiciones de liderazgos personalistas, no puede ser ajeno al papel clave que cumplen las instituciones representativas en los regímenes democráticos.

\section{b) Contribuciones para fortalecer la dimensión parti- cipativa, horizontal y popular de la democracia des- de sus modos de ejercicio}

El segundo problema remite a la tensión entre el deseo de participación social horizontal del demos y la inevitabilidad de los mecanismos de representación vertical de las democracias modernas. Esta tensión nos conduce a los aportes de las perspectivas democráticas (clásicas) y socialistas (acompañadas por algunas visiones republicanas de matriz comunitarista o popular) y a las luchas de los movimientos sociales para promover las formas de participación popular y comunitaria por afuera de los vínculos de representación política y del decisionismo personalista de los líderes, así como para garantizar el cumplimiento de los derechos sustantivos de las mayorías populares y alcanzar la igualdad social.

Vimos anteriormente la tradicional contraposición que se plantea entre la teoría de la representación absoluta de Hobbes y la visión participativaasamblearia de Rousseau. Sin embargo, un análisis más profundo de la obra de Rousseau nos permite observar que, en el momento de analizar el plano óntico, el ginebrino termina aceptando la inevitabilidad de ciertas formas de representación política, dada la imposibilidad de retornar al esquema de la democracia clásica ateniense en la Modernidad (Rousseau, 1995). Además, como destaca Manin (1992, p. 13), aunque en "El contrato social" Rousseau rechaza la representación política, al ser la expresión soberana del pueblo "inalienable" e "indivisible", en sus últimos textos acepta explícitamente el proceso de representación mediante diputación, dada la imposibilidad del auto-gobierno asambleario del pueblo ${ }^{30}$.

En la misma línea, Laclau (2005a) destaca en "La razón populista" que Rousseau fue el primero en plantear una alternativa al problema de la representación democrático-popular, alejado del modelo de parlamentarismo lockeano. Contra lo que pueda suponerse, el ginebrino no era contrario al principio de representación política. En realidad, era "receloso" de la representación, pero "la aceptaba como un mal menor, dada la imposibilidad de una democracia directa en comunidades grandes, como los modernos Estados Nación". En ese marco, la "solución" que halló a este problema central de la Modernidad consistía en que "el representante debe transmitir lo más fielmente posible la voluntad de aquellos a quienes representa" (Laclau, 2005a, p. 200).

Sin embargo, desde el posfundacionalismo sabemos que el representante, al tomar decisiones y actuar políticamente en un lugar diferente de los representados, no puede "transmitir la voluntad" de aquellos a quienes representa o actuar por "mandato imperativo", sino que necesariamente incorpora un "agregado" o "plus" en el proceso de representación política (Laclau, 2005a, p. 200). Como un modo de sortear este problema, complejizando los aportes del post-estructuralismo, Laclau se refirió a la necesidad de los liderazgos "populistas" de generar "un punto de identificación social" (p. 201) y de integrar equivalencialmente las "demandas insatisfechas" del "Pueblo", realizando un "llamado público a los de abajo" (p. 157). De este modo, recuperando elementos de la concepción clásica de la soberanía popular, pero desde el rol democratizador del líder populista, pareció hallar una solución al problema de la democracia como gobierno del pueblo (en tanto ideal) y la inevitabilidad del papel de los representantes políticos (como realidad fáctica) en tiempos modernos, evitando el decisionismo hobbesiano-schmittiano, la representación parlamentarista lockeana y el peligro del anti-pluralismo del planteo rousseauniano.

En esta etapa Laclau también mantuvo la existencia de una voluntad política relativamente sedimentada en los representados, cuya voluntad debía de algún 
modo representar en la dinámica política. En ese sentido, reconoció que "lo que está siendo representado existe como un objeto pleno con anterioridad y en forma totalmente separada del proceso de representación" ${ }^{\prime 1}$ (Laclau, 2005a, p. 206). Sin embargo, a diferencia de sus trabajos de los años '80, priorizó el movimiento de re-presentación del líder populista mediante la "nominación" performativa que constituye esa voluntad, quitándole autonomía a la voz los representados. En este sentido, señaló que la "tarea" del representante político debía consistir en "proveer un punto de identificación que constituirá como actores históricos a los sectores que está conduciendo" (p. 201). El peligro óntico de este déficit conceptual es que un liderazgo, en el nombre de la defensa de los intereses populares y la voluntad del Pueblo, aplique verticalmente políticas percibidas socialmente como contrarias a las voluntades de sus representados, sin que estos tengan posibilidad de juzgar y validar su autoridad, brindándole representatividad, es decir, legitimidad social.

Ahora bien, en algunos trabajos posteriores a "La razón populista", Laclau profundizó en esta tensión óntica, destacando el peligro que el líder populista se autonomice en exceso de las demandas de sus representados, dejando a un lado la necesaria "escucha" de aquellos sectores a quienes debe priorizar para ser "representativo". En ese marco, refiriéndose a los gobiernos populistas de la región, en un texto del año 2006 señaló como "una legítima cuestión" determinar "si no hay una tensión entre el momento de la participación popular y el momento del líder", preguntándose "si el predominio de este último no puede llevar a la limitación de aquélla" (Laclau, 2006a, p. 60). Para evitar el peligro de una extrema "burocratización" del líder frente a las masas, Laclau propuso distinguir entre un "populismo burocrático" y un "populismo democrático y altamente participativo", vinculando a este último a los populismos de "centroizquierda" de América Latina (en particular, el chavismo y el kirchnerismo) (pp. 61-62). Sin embargo, pese a estos señalamientos, son escasas sus reflexiones críticas sobre los límites de los gobiernos populistas realmente existentes y los modos de solucionar este problema del ejercicio de la representación política.

Al no profundizar sobre estos aspectos democrático-populares, ni analizar posibles soluciones a esta problemática en los procesos políticos contemporáneos, Laclau terminó por resolver el asunto, a fin de cuentas, priorizando el papel "ordenador" del líder. Así, a diferencia de Rousseau (1995) y su tesis del "mandato imperativo" como alternativa viable a la soberanía "inalienable" e "indivisible" del pueblo, el teórico argentino no examinó las formas de democracia participativa y comunitaria del demos, colocando el eje en la organización vertical desde el poder estatal. De este modo, no recuperó los aspectos horizontales, populares y ascendentes que se derivan de la obra del pensador ginebrino, las mismas que han sentado las bases de las formas participativas y directas de la democracia moderna (Macpherson, 1982). Estos déficits teóricos presentan serias implicancias normativas. Ello se debe a que pueden traducirse, en la práctica discursiva fáctica, en la presencia de liderazgos políticos que, en nombre de los intereses del Pueblo, la Nación, la Clase Universal o el Partido, se autonomicen plenamente de las masas y realicen una "revolución pasiva" (Gramsci, 1984).

El peligro de una burocratización extrema del líder fue destacado tempranamente por Gramsci, al observar las derivaciones del socialismo "realmente existente" en la Unión Soviética, luego profundizadas por la dictadura de Stalin. Ello lo condujo a distinguir entre la posibilidad de que emerja un líder "democrático", frente a las potenciales desviaciones "burocráticas" (Gramsci, 2011). Lamentablemente, el problema central del liderazgo popular que deriva en totalitario, destacado también por autores como Mondolfo (1973) y el propio Lefort (1990 y 2011), en su crítica al "totalitarismo" soviético y al liderazgo "egócrata" de Stalin, no fue profundizado ni resuelto por la teoría del populismo de Laclau. En ese sentido, en consonancia con el abandono sintomático del proyecto "posmarxista", subordinó el análisis de las formas de participación popular, horizontal y autónoma de los sectores subalternos en las democracias contemporáneas, frente a la construcción performativa del "pueblo" por parte del líder populista.

En otras palabras, Laclau pretendió alejarse del verticalismo extremo de Hobbes y del potencial totalitarismo de un uso anti-liberal de Rousseau, pero sin reflexionar sobre la dimensión horizontal-participativa-popular de este último. Este problema se observa en el momento en que la teoría del populismo abandona las referencias a la "democratización radical" y a la defensa de la "igualdad" y las formas de participación social autónomas de los nuevos movimientos sociales (Laclau, 1993; Laclau y Mouffe, 1987), hacia una primacía conceptual y normativa de la representación estatalista y las decisiones políticas del líder populista, de su última etapa (Fair, 2015). Los intentos de solucionar esta tensión apelando al concepto de 
"demandas sociales insatisfechas" de "los de abajo" y reconociendo la tensión entre participación y representación política, resultan insuficientes.

Como una respuesta a este problema teórico-político, proponemos otorgar una mayor autonomía y agentividad al demos (como titular de la soberanía) en la toma de decisiones públicas, sin desconocer que la representación política es ontológica. De este modo, procuramos profundizar en los aspectos populares de la democracia desde sus modos de ejercicio óntico, y al mismo tiempo acentuar el carácter horizontal del lazo de representación política mediante liderazgos en las democracias actuales, a partir de:

1. Redefinir al concepto de "pueblo" como "sectores subalternos", priorizando la satisfacción de las demandas sociales insatisfechas de los trabajadores y sectores populares, como agentes que conforman el campo popular.

2. Promover y garantizar, en los discursos verbales y en las prácticas (discursivas) fácticas, la difusión, extensión y ejercicio de las formas de participación, movilización y organización social y popular, resguardando la autonomía de los sectores subalternos frente a las directrices e imposiciones del poder estatal.

3. En el marco del punto anterior, estimular y favorecer las múltiples formas de asociación, organización, participación y movilización política y social de los sectores populares y subalternos, desde mecanismos horizontales, autónomos e independientes del control y la imposición arbitraria de las directrices del poder estatal. Ello incluye desde la institucionalización y el uso asiduo de mecanismos formales de participación popular (como asambleas, referéndums, plebiscitos, iniciativas populares, presupuestos participativos, elecciones internas libres y abiertas de candidatos), hasta la promoción y el respeto efectivo a la autonomía en las decisiones y los modos de acción pública de los movimientos sociales y populares, frente al poder arbitrario del Estado.

4. Promover y garantizar desde el Estado la escucha, la capacidad decisoria, el reconocimiento social y el cumplimiento efectivo de las demandas privilegiadas enunciadas por los sectores subalternos, tanto a través de una efectiva participación popular y decisión vinculante en los mecanismos formales institucionalmente establecidos, como garantizando una autonomía efectiva de los grupos subalternos para organizarse y decidir sobre sus formas de participación y movilización popular y sus estrategias de reivindicación y acción social.

5. Promover y garantizar, en los discursos verbales y en las prácticas sociales, una efectiva inclusión social de los sectores subalternos, priorizando la satisfacción de sus necesidades básicas y el cumplimiento de los derechos sociales y comunitarios (vivienda, trabajo y salario digno, salud y educación pública de calidad, etc.).

La delimitación de estas dos dimensiones tendientes a la construcción de una teoría y práctica de la democracia participativa, horizontal y plural, no buscan (ni tampoco podrían) solucionar los múltiples problemas que se presentan en la dinámica política entre las acciones, decisiones y reacciones de los poderes institucionales de gobierno y las complejas interacciones del Estado con los actores sociopolíticos (organizados o no). Sin embargo, entendemos que resultan cruciales para evitar los peligros que se derivan de una excesiva autonomía decisoria de los liderazgos políticos y para consolidar el ejercicio de una democracia radicalizada y plural, desde una izquierda posfundacional.

\section{A MODO DE CONCLUSIÓN}

Este trabajo analizó el problema de la representación política de lo social en las democracias contemporáneas, teniendo en cuenta las tensiones teóricas y políticas entre las tradiciones democráticas, liberales y republicanas y el papel que asumen los liderazgos políticos y el entramado institucional. En la primera parte, se examinaron los debates sobre la representación política desde las perspectivas predominantes de la Ciencia Política latinoamericana y las críticas desde las concepciones alternativas, incluyendo a las teorías de la metamorfosis de la representación, las visiones schmittianas y las teorías posestructuralistas de la representación política. En la segunda parte, se analizaron los vínculos y tensiones entre la teoría posfundacional del populismo de Laclau y la Ciencia Política neo-institucionalista. En primer lugar, se destacó que, desde la propuesta teórica del pensador argentino, las lógicas del populismo y el institucionalismo, del mismo modo que las lógicas de la diferencia y la equivalencia, constituyen construcciones político-discursivas que se estructuran social e históricamente desde el orden significante, de manera tal que carecen de esencias o fundamentos ahistóricos y universalistas. En razón de estas características, desde la perspectiva posfundacional 
de Laclau las disyunciones estrictas y tajantes de las lógicas sociales se disuelven en la contingencia del análisis histórico-político. Al desplazarse al análisis político, Laclau pone en evidencia que no existe una disyunción entre las lógicas políticas. En este sentido, destaca la existencia de una tensión permanente e irresoluble entre la lógica de la equivalencia y de la diferencia, que se necesitan entre sí como condiciones necesarias para la construcción de lo social. Ello se debe a que la equivalencia no puede eliminar las diferencias sin autodisolverse y a que no existe una diferencialidad pura. A partir de la aceptación de esta tensión constitutiva, Laclau define al populismo como una lógica política que implica una articulación variable de la equivalencia y la diferencia. Sin embargo, la proporción entre la equivalencia y la diferencia se inscribe en un espacio de variaciones muy amplio en la dinámica política. En ese sentido, su tesis sostiene que el populismo se caracteriza por priorizar la articulación equivalencial de las demandas y por realizar una partición tendencial del espacio social en dos partes antitéticas (el pueblo contra el poder), relegando el carácter diferencial. Para poder analizar a los proyectos populistas, indica que se debe partir del grado de extensión de la cadena equivalencial que unifica las demandas sociales. Ello implica distinguir entre discursos más institucionalistas, en los que predomina en proporción la lógica de la diferencia, y aquellos más populistas, en los que predomina la ruptura y existe una tendencia a dividir lo social en dos partes antagónicas. A partir de la incorporación de un continuum histórico, se puede identificar hasta qué punto un movimiento se acerca tendencialmente a la diferenciación extrema o a la división pura del espacio social. Sin embargo, ambos extremos son, por definición, imposibles. En el primer caso límite, ello implicaría un individualismo tan extremo que no existiría ningún tipo de articulación equivalencial ni de frontera política y la misma lucha política perdería todo sentido. En el segundo caso límite, se presentaría el extremo opuesto de la eliminación de todo carácter diferencial del significante, lo que supondría subsumir el concepto de equivalencia en la plena identidad de lo social. El reconocimiento de las variaciones históricas que presuponen ambas lógicas de un modo complejo, conduce a Laclau a concluir que todo movimiento político presupone al menos cierto grado de populismo (y cierto grado de institucionalismo). Al analizar a los gobiernos progresistas de América Latina, el teórico argentino refuerza la existencia de una interpenetración compleja entre el populismo y el institucionalismo, que se deriva del análisis de la proporción de gradientes entre la lógica de la equivalencia y la lógica de la diferencia. De este modo, habilita a analizar de forma comparada los casos híbridos que combinan elementos populistas e institucionalistas en distinta proporción.

Una segunda discusión remite a las tensiones entre la teoría del populismo y la cuestión del pluralismo. En relación a este eje, se destacó que la teoría del populismo tampoco plantea una disyunción con las formas pluralistas. Por un lado, la perspectiva posfundacional de Laclau asume que toda operación hegemónica debe mantener un desplazamiento metonímico entre lo particular y lo universal, conservando la aceptación del carácter diferencial y particular de lo social. Por el otro, se hallaron algunos fragmentos de "La razón populista" que refieren a la complementación entre las demandas populares de la tradición clásica y la defensa de las libertades civiles y políticas del liberalismo. Sin embargo, en el marco del esquema formal del populismo y la exacerbación del estiramiento conceptual del fenómeno, en su última etapa Laclau relegó las diferencias que existen entre un orden autoritario o autocrático (iliberal) y un orden dictatorial o totalitario (antiliberal) y subordinó los vínculos y afinidades con el liberalismo político radical. Ello se tradujo en una escasa conceptualización de los aspectos institucionales y pluralistas, lo que redujo la capacidad explicativa de la especificidad de los fenómenos histórico-políticos. No distinguió, por ejemplo, entre las pretensiones hegemónicas de los populismos latinoamericanos, que mantuvieron el desplazamiento particular-universal, frente al carácter fundamentalista y anti-pluralista de los totalitarismos, que pretendieron encarnar la sustancia de lo social, triturando las diferencias particulares.

Tomando en cuenta estos déficits teóricos y conceptuales y sus implicancias normativas para la consolidación de una democracia radicalizada y plural, en la tercera parte se desarrolló una crítica a la teoría del populismo de Laclau. Para ello, se incorporó una doble operación analítica. En primer lugar, se distinguió conceptualmente entre los elementos institucionales, administrativos y pluralistas de la tradición liberal, que aparecen yuxtapuestos en el esquema laclauciano. En segundo término, se distinguió entre las formas populistas (posfundacionales) e ideológicas (fundacionales), con base en la diferencia de gradientes que existe entre los conceptos de autoritarismo, dictadura y totalitarismo. A partir de allí, se identificaron cuatro lógicas de construcción de las identidades políticas y del orden social, distinguiendo entre las lógicas popu- 
listas e institucionalistas desde los aportes de Laclau referidos al predominio de la lógica equivalencial o diferencial y el reconocimiento del pluralismo, y las lógicas totalitarias y tecnocráticas, que representan a las formas ideológicas y fantasmáticas que pretenden encarnar la transparencia y plenitud de lo social, eliminando las particularidades constitutivas y negando la contingencia del orden social.

En la última parte, se examinaron los déficits normativos de la teoría del populismo, analizando la doble tensión que existe entre la representación política vertical y la participación popular horizontal y entre las decisiones personalistas y la aceptación del pluralismo social e institucional. Con el objeto de responder a estos problemas, se identificaron y conceptualizaron dos dimensiones tendientes al desarrollo de una teoría y práctica posfundacional de la democracia. En primer lugar, una dimensión plural, vinculada al respeto al pluralismo social, las libertades, derechos y garantías individuales y los mecanismos institucionales del Estado de derecho de las democracias representativas. En segundo término, una dimensión participativa, vinculada al eje horizontal y popular de la democracia clásica. La primera dimensión, que condensa aportes de las tradiciones del liberalismo radical y el republicanismo, se relacionó a la difusión del poder político para promover y garantizar la defensa de las libertades civiles, políticas y culturales básicas que hacen a los seres humanos individuos sociales diferentes entre sí y con derecho a expresarse, opinar, asociarse, movilizarse y participar en el espacio público, sin temor al castigo físico o las imposiciones arbitrarias por parte del Estado. También se incluyó el reconocimiento a la libertad de culto y de cátedra, el derecho a un juicio justo y ecuánime y a disponer de una vida privada que sea ajena a las directrices del poder estatal. Asimismo, se incorporó un eje vinculado al resguardo del patrimonio público, el control institucional y los mecanismos de división y equilibrio de poderes del Estado de Derecho, que deben garantizar el funcionamiento efectivo de los frenos y contrapesos y de las agencias de control periódico y sanción de los actos ilícitos de gobierno. Estos elementos deben institucionalizarse mediante el sistema legal, de manera tal de promover su universalización y estabilidad social, reforzando su fuerza performativa, bajo la amenaza coactiva del Estado.

La segunda dimensión, vinculada a los aportes de las tradiciones clásicas y jacobinas de la democracia, remite al aspecto participativo, horizontal y popular de la democracia como gobierno del pueblo, promoviendo la difusión democrática, horizontal y popular del poder político hacia el demos como agente soberano. En primer lugar, se redefinió el concepto de pueblo como sectores subalternos, de manera tal de priorizar las demandas sociales insatisfechas de los trabajadores y sectores populares, como agentes que conforman el campo popular. Esta dimensión se vinculó a la necesidad de fomentar y garantizar las formas de participación y decisión popular y comunitaria desde mecanismos de democracia directa y semi-directa, y resguardar la autonomía de los movimientos sociales y los sectores subalternos para promover sus formas propias de organización, participación y acción social por afuera de los vínculos de representación política y de las directrices e imposiciones del poder estatal. Se destacó, además, la necesidad de los representantes políticos de promover la escucha, el reconocimiento y la ampliación de los derechos sociales y comunitarios sustantivos de los grupos subalternos y oprimidos, promoviendo políticas públicas universalistas que prioricen la satisfacción de sus necesidades básicas y contribuyan a una efectiva igualdad económica y social.

Mediante el desarrollo de esta propuesta se ha procurado radicalizar la doble dimensión ascendente y descendente del proceso de representación política en las democracias actuales, evitando dos peligros potenciales del ejercicio del gobierno. El primer peligro es el de caer en regímenes burocráticos, autocráticos, dictatoriales, o incluso, en retornar a las experiencias totalitarias, guiados por esquemas esencialistas y fundamentalistas que trituren las diferencias y particularidades sociales. El segundo peligro es el de caer en formas elitistas, tecnocráticas y neoconservadoras, que socaven los derechos sociales sustantivos de los sectores subalternos, promuevan modelos socialmente injustos y excluyentes y rechacen la legitimidad de las formas de participación y movilización social de las masas populares.

Finalmente, se ha pretendido reflexionar críticamente acerca de los avances y límites de la dinámica de representación política mediante liderazgos de los populismos históricos y actuales en América Latina. Por un lado, estos gobiernos han promovido valiosas políticas de reconocimiento, ampliación y universalización de derechos sustantivos y reparación de injusticias históricas, fomentando la inclusión política, económica y social radicalizada y la dignificación como sujetos de derecho de los trabajadores, sectores populares y oprimidos. Al reconocer este papel 
socialmente democratizador, reparador de injusticias, estigmatizaciones y exclusiones sociales históricas y ampliador de derechos sustantivos institucionalizados para las mayorías populares, se ha pretendido trascender a las concepciones procedimentalistas, neoliberales y conservadoras, que reducen los vínculos de representación política a factores meramente emotivos, irracionales y manipulativos por parte de los líderes carismáticos y "demagógicos". Estas visiones procedimentalistas y tecnocráticas, en nombre de la crítica a los gobiernos "populistas", han promovido durante los años '90 una concepción elitista y estrecha sobre la democracia, de matriz neoliberal, que es contradictoria con los axiomas básicos de una democracia integral. Por el otro, se han pretendido destacar los límites de estas experiencias históricas para lograr una democracia representativa de calidad, al promover discursos verbales y prácticas sociales burocratizadas, verticalistas y reñidas con el respeto al pluralismo social y a los mecanismos de equilibrio de poderes y control institucional del Estado de Derecho.
Entendemos que para radicalizar y consolidar a la democracia, desde una izquierda posfundacional, se deben integrar sus aspectos sustantivamente igualitarios, participativos y plurales. Ello implica promover y garantizar la ampliación efectiva de las formas de democratización igualitaria, la inclusión social sustantiva de los sectores subalternos y las mayorías populares y la participación y movilización social del demos desde un sentido horizontal-popular y autónomo de las directrices e imposiciones del poder estatal, junto al respeto a las diferencias y particularidades y el reconocimiento efectivo del pluralismo social, cultural e institucional. De este modo, procuramos evitar las prácticas burocráticas y elitistas de gobierno y el riesgo de repetir las experiencias fundamentalistas y esencialistas del pasado, aunque sin caer en un procedimentalismo parlamentarista o en un tecnocratismo gestionario y conservador, que reduzca el valor de la democracia a un orden socialmente excluyente, vacío de contenido popular y limitado a sus aspectos meramente formales, técnicos e institucionales.

\section{NOTAS}

1. Países como Uruguay, Costa Rica, Chile y Colombia han sido destacados como excepciones de esta lógica movimientista, aunque solo los dos primeros fueron situados habitualmente como ejemplos de una democracia formalmente institucionalizada.

2. El impacto de esta concepción crítica de los liderazgos personalistas provino desde los analistas de Europa Continental, fuertemente influidos por experiencias históricas como el bonapartismo y, sobre todo, el fascismo y el nazismo (Novaro, 2000, p. 65). También ha sido relevante la influencia del planteo weberiano sobre la emotividad del vínculo político y el carácter extra-institucional del líder carismático, un planteo que ha sido radicalizado por las visiones predominantes de la Ciencia Política (p. 128).

3. Los análisis politológicos de los años '90 solían destacar la estabilidad institucional del sistema político venezolano que emergió de la firma del Pacto de Punto Fijo (1958) y situaban dentro de los regímenes "exitosos" al sistema parlamentario español. Ambos "modelos", sintomáticamente, colapsarían en la última década y media.

4. Los abordajes neo-institucionalistas de la Ciencia Política analizaron los efectos regresivos de estos cambios sobre la función agregativa de los partidos políticos tradicionales, destacando su transformación en partidos "atrapatodo" (catch all) (Kirchheimer), "profesionales-electorales" (Panebianco) o "cartel" (Mair), mientras que los estudios electorales cuantificaron el incremento en los niveles de abstencionismo, voto en blanco y volatilidad electoral.

5. La teoría decisionista de Schmitt, escrita al calor de la crisis de la República de Weimar, amalgamaba aportes de Bodin, Grocio, Pufendorf y en particular de Hobbes, para construir una teoría realista y anti-liberal. Sobre el particular, véase Baldioli y Leiras (2010).

6. En realidad, Schmitt tampoco desconoce el papel del Parlamento, en el momento en que la decisión del líder político mantiene el respeto al orden jurídico normativo, que tipifica formalmente sus funciones (Schmitt, 2005 , p. 23 y ss.). Sin embargo, a diferencia de estos autores, no reconoce un espacio público de manifestación y presencia de lo representado, ni hace referencia a la necesidad de respetar el pluralismo social e institucional, manteniendo una visión verticalista, descendente y anti-pluralista (Novaro, 2000, p. 92 y p. 165). Por otra parte, cabe destacar que su teoría de la representación política fue mutando en el transcurso de su obra. Ya en 1928
Schmitt incorporó un elemento de "identidad sustancial", mientras que en 1933 (año de ascenso de Hitler como Canciller) utilizaría la crítica al régimen parlamentario para justificar la "revolución legal" hitleriana, basada en la integración totalitaria del Estado con el movimiento y el pueblo, sin ninguna mediación del orden institucional (véase Novaro, 2000, pp. 230-234).

7. Recordemos que Tocqueville parte de la base que la "esencia" los "gobiernos democráticos" es el "imperio de la mayoría". Sin embargo, luego indica que resulta "detestable" la "máxima" que sostiene que "la mayoría de un pueblo tiene derecho a hacerlo todo", ya que ello implica librar ese poder para "actuar sin control". A partir de allí, advierte sobre el "germen de la tiranía" que se encuentra en la base de esta "omnipotencia" de las mayorías, que "favorece el despotismo del legislador" y "la arbitrariedad del magistrado", dejando a merced las libertades y derechos de las minorías (Tocqueville, 1969, capítulo XI, especialmente pp. 151-161).

8. Básicamente, las tesis de Rousseau (1995) que refieren a que los hombres nacen libres e iguales y deben permanecer como tales y su defensa de la soberanía popular y la participación social. 
9. Lefort incluye en esta lógica "totalitaria" a una multiplicidad de liderazgos "egócratas" que pretendieron encarnar el "cuerpo social" como totalidad y "triturar las diferencias", incluyendo a Lenin, Stalin, Mao, Kim II Sung, Fidel Castro y Hitler (Lefort, 2011, pp. 66 y 186).

10. Para más detalles de esta concepción teórica compleja y de sus vínculos y tensiones con el post-estructuralismo francés, véase Fair (2014).

11. Laclau se refiere al papel del líder como eje articulador, pero no como origen necesario del vínculo de representación de lo social. De este modo, aunque la conformación de las identidades "Ilega a un punto en el que la función más homogeneizante es llevada a cabo por un nombre propio: el nombre del líder", también advierte que esto se produce "en su expresión más extrema" (Laclau, 2005a, p. 130; Laclau, 2009, p. 60) Además, afirma que Freud "se apresura demasiado en pasar de apuntar el amor por el líder como condición central de la consolidación del vínculo social, a la afirmación de que é constituye el origen de ese vínculo" (Laclau, 2005a, p. 109). Como señala en un texto del 2006: "No es que el líder sea el origen del movimiento, sino que, sin ese punto de aglutinación, el movimiento no podría forjar su unidad, se dispersaría entre los elementos que lo componen" (Laclau, 2006b, p. 118). Sobre los límites de la interpretación freudiana de Laclau para pensar el vínculo social, véase Ípola (2009).

12. Cabe destacar que, al coquetear con la perspectiva lacaniana de la identificación en torno al "objeto parcial", por momentos Laclau (2005a) excluye de su esquema a la figura del líder, habilitando la posibilidad de pensar en una articulación popular condensada en torno a ciertos "objetivos" o "símbolos" que "se convierten en los nombres de su ausencia" (p. 149).

13. El debate en torno a la democracia delegativa y la teoría (neo)decisionista excede el marco del presente trabajo. Para una crítica que engloba a ambas perspectivas desde el campo marxista, véase Bonnet (2008).

14. Existen diversas vertientes dentro del liberalismo, algunas de las cuales presentan una visión más social y democrática (como el llamado liberalismo social) y otras una más visión más economicista y conservadora (como el llamado libertiarismo), aunque todas ellas comparten el privilegio del valor de las libertades individuales (en un sentido defensivo), sobre la igualdad social.

15. Recordemos que la lógica de la equivalencia corresponde a una "lógica de simplificación del espacio político, que expande los elementos que pueden sustituirse el uno al otro". Por su parte, la "lógica de la diferencia" implica una "lógica de expansión y complejización del espacio político, que expande la relación combinatoria de posiciones" (Laclau y Mouffe, 1987, p. 174). Mientras que la lógica de la diferencia "establece localizaciones particulares", la lógica de la equivalencia "universaliza cierta particularidad" (Laclau, 2003a, p. 196). En otras palabras, mientras que la primera "universaliza una cierta particularidad, en tanto esta es sustituible por un número indefinido de otras particularidades" o, lo que es lo mismo, trasciende su particularidad inherente a través del establecimiento de articulaciones equivalenciales, la segunda "establece localizaciones particulares dentro del espectro social", es decir, subvierte la lógica universalizadora del sistema, a partir de la aparición de diferencias particulares que revelan su propia imposibilidad (Id.).

16. Como señala en un pasaje, "si la lógica equivalencial tiende a erradicar la relevancia de toda localización diferencial, éste es sólo un movimiento tendencial, siempre resistido por la lógica de la diferencia, que es esencialmente anti-igualitaria” (Laclau, 1996, p. 81). La disolución del carácter diferencial del significante equivaldría, en términos políticos, a un totalitarismo, que disolvería el propio carácter posfundacional de la hegemonía.

17. Como lo sintetizaría en una entrevista del 2007: "Jorge Abelardo Ramos decía que la sociedad nunca se polariza entre el manicomio y el cementerio. Es decir, el cementerio sería un régimen completamente institucionalizado, mientras que el manicomio es el puro antagonismo. Siempre lo que se da es una situación intermedia, en que lo político opera a través de las lógicas equivalenciales, articulando las demandas, y lo institucional también tiene su parte. No hay nunca un populismo puro"
("La política es caminar entre dos precipicios", entrevista a Ernesto Laclau, Pagina 12, 21 de mayo de 2007).

18. Recordemos que, según Laclau, "ninguna lógica hegemónica puede dar cuenta de la totalidad de lo social y constituir su centro, ya que, en tal caso, se habría producido una nueva sutura y el concepto mismo de hegemonía se habría autoeliminado" (Laclau y Mouffe, 1987, p. 186). En este sentido, la construcción de hegemonías, definidas como la universalización de demandas particulares que trascienden su inherente particularidad, es siempre precaria, en tanto fue alcanzada a través de un debilitamiento del particularismo por un universalismo que resulta imposible por definición (Laclau, 1996, p. 102).

19. Por momentos, Laclau intentó matizar los peligros que pueden derivarse de su esquema formal, al plantear la distinción normativa entre populismos "de izquierda" y "de derecha" (Laclau, 2005a, p. 151). Además, en textos y entrevistas posteriores asumió una defensa explícita de los gobiernos de "centroizquierda" latinoamericana (en particular, de Chávez y Kirchner), en su lucha contra la "derecha" neoliberal (Laclau, 2006a), así como su preocupación por el "desarrollo de un populismo de extrema derecha en la Europa contemporánea" (Laclau, 2002 , p. 6). Sin embargo, no profundizó en estos aspectos.

20. En este sentido, este autor destacó al kirchnerismo como un ejemplo de construcción populista opuesto a la "tentación administrativista" de las demandas, antes que al institucionalismo (Balsa, 2013, p. 20).

21. En años posteriores, el peronismo sancionó leyes laborales adicionales, como la Ley de organización laboral, la Ley de negociación colectiva y la Ley de Seguridad social.

22. Otros estudios retomaron esta propuesta, presente también en los textos de Melo, para examinar las combinaciones históricas entre la lógica populista y la institucionalista en la identidad kirchnerista.

23. Laclau (2005a) reconoce que su teoría formal del populismo implica "vaguedad e imprecisión" (p. 128) y que el empleo de un lenguaje "impreciso y fluctuante" corresponde a un "componente esencial de cualquier operación populista" (p. 151). 
24. Laclau reconoce en un fragmento que en experiencias como el etnopopulismo "no hay ninguna posibilidad de pluralismo" (Laclau, 2005a, p. 244), pero no profundiza sobre este problema.

25. No es motivo de este trabajo examinar los antecedentes teóricos de esta concepción, que remiten a una larga tradición de pensamiento liberal y republicana que condensa aportes de autores como John Stuart Mill, Tocqueville, Montesquieu, Weber, los Federalistas, Dahl y las teorías neoinstitucionalistas.

26. Por razones de espacio no resulta posible analizar aquí las distintas vertientes internas y las propias divergencias teórico-políticas (y algunas convergencias) que existen entre el liberalismo y el republicanismo. La más detallada e influyente síntesis de estas tradiciones desde la Ciencia Política latinoamericana corresponde a los análisis de la última etapa de la obra de Guillermo O’Donnell (2007).

27. Nuevamente, excede el marco de este trabajo el análisis de los anteceden-

\section{BIBLIOGRAFÍA}

Aboy Carlés, G. (2001). Fundamentos teóricos para el estudio de las identidades políticas. En Aboy Carlés, G. Las dos fronteras de la democracia argentina: la reformulación de las identidades políticas de Alfonsín a Menem. Rosario: Homo Sapiens, pp. 21-74.

Aboy Carlés, G. (2010). Las dos caras de Jano: acerca de la compleja relación entre populismo e instituciones políticas. Pensamento Plural, 7, pp. 21-40.

Aboy Carlés, G. (2013). De lo popular a lo populista, o el incierto devenir de la plebs. En Aboy Carlés, G., Barros, S. y Melo, J. (comps.). Las brechas del pueblo. Reflexiones sobre identidades populares $y$ populismo. Buenos Aires: UNGS-UNDAV, pp. 17-40.

Aboy Carlés, G. (2014). El nuevo debate sobre el populismo y sus raíces en la transición democrática: el caso argentino. Colombia Internacional, 82, pp. 23-50.

Anónimo (2002). El análisis político del discurso: entre la teoría de la hegemonía y la retórica. Entrevista a Ernesto Laclau. De Signis, 2, pp. 1-7.

Arditi, B. (2010). Post-hegemonía: la política fuera del paradigma postmarxista habitual. En Cairo, H. y Franzé, J. (comps.), tes teóricos, que remiten a autores como Sartori y Zakaria, entre otros. En cuanto a los ejemplos históricos, existe consenso en la bibliografía (liberal) especializada en considerar al nazismo como un totalitarismo (aunque algunos autores lo consideran una dictadura), a los golpes militares como gobiernos dictatoriales y a gobiernos como el de Perón en Argentina como autoritarios o autocráticos, para distinguirlo cualitativamente del control total y la ausencia de todos los indicadores de la poliarquía de los primeros.

28. En "Muerte y resurrección de la teoría de la ideología" Laclau (2004) refiere al "efecto ideológico" como "la creencia en que hay un ordenamiento social particular que aportará al cierre y la transparencia de la comunidad" (p. 21). Ello aplica a cualquier "objeto particular" que pretende encarnar, ilusoriamente, "la plenitud imposible de la comunidad", ya sea transformando la "equivalencia" en una "identidad" resuelta en el "Uno indiferenciado", como en los totalitarismos, o bien mediante el intento

Política y cultura. Madrid: Biblioteca Nueva, pp. 159-193.

Baldioli, A. y Leiras, S. (2010). Democracia, estado de excepción y decisionismo político: consideraciones y conceptos. En Leiras, S. (comp.). Estado de excepción y democracia en América Latina. Rosario: Homo Sapiens, pp. 25-51.

Balsa, J. (2013). Sobre lógicas y discursividades. En Balsa, J. (comp.). Discurso, política y acumulación en el kirchnerismo. Buenos Aires: UNQ-Centro Cultural de la Cooperación, pp. 15-30.

Barros, S. (2006). Inclusión radical y conflicto en la constitución del pueblo populista. Confines, 2/3, pp. 65-73.

Bobbio, N. (1993). El futuro de la democracia. Buenos Aires: Fondo de Cultura Económica.

Bobbio, N. (2012). Liberalismo y democracia. México: Fondo de Cultura Económica.

Bonnet, A. (2008). La hegemonía menemista. Buenos Aires: Prometeo.

Botana, N. (2006). Poder y hegemonía. Buenos Aires: Emecé.

Derrida, J. (1989). La escritura y la diferencia. Barcelona: Anthropos. que "la lógica equivalencial fuera eliminada", vinculado al "ideal de prácticas administrativas puras, no políticas" ( $p$. 55). Sobre el concepto de ideología en Laclau, véase Fair (2011).

29. Ello incluye desde la crítica a las ideologías totalitarias y esencialistas (como el nazismo y el fascismo), hasta la crítica a las ideologías tecnocráticas y cientificistas (como el neoliberalismo).

30. Novaro también destaca que "ni siquiera la democracia rousseauniana elimina la representación. Apenas la interioriza en los ciudadanos, pues en ellos se realiza la automediación entre los hombres particulares y la voluntad general" (Novaro, 2000, p. 210).

31. En este sentido, por momentos se refirió a los conceptos de "lumpenproletariado" de Marx y de "masa marginal" de Nun, aunque sólo para destacar que los actores que irrumpen son los "marginales" y los que "están fuera del sistema" (Laclau, 2005a, pp. 181-190).

Fair, H. (2011). El concepto de ideología y la tensión entre conflicto, consenso y orden en las teorías de Laclau y Zizek. Leviathan, 3, pp. 146-189. Disponible en: http://studylib.es/doc/6306008/ el-concepto-de-ideolog\%C3\%ADa-y-latensi\%C3\%B3n-entre-conflicto--co...

Fair, H. (2014). Transformaciones, rupturas y continuidades entre la perspectiva de Ernesto Laclau y la tradición (post) estructuralista. En Karckzmarczyc, P. (comp.), El sujeto en cuestión. Abordajes contemporáneos. La Plata: Universidad Nacional de La Plata, pp. 187-240. Disponible en: https://philpapers.org/ archive/KARESE.pdf

Fair, H. (2015). ¿Qué queda del posmarxismo en la teoría de la hegemonía de Ernesto Laclau? Tres etapas histórico-políticas y tres desplazamientos en su concepción normativa. Crítica Contemporánea, 5, pp. 41-81. Disponible en: http://cienciassociales. edu.uy/institutodecienciapolitica/wpcontent/uploads/sites/4/2015/12/ Fair.pdf

Garretón, M. (1998). Representatividad y partidos políticos: los problemas actuales. Revista Argentina de Ciencia Política, 2, pp. 99-127. 
Gramsci, A. (1984). Notas sobre Maquiavelo, sobre la política y sobre el Estado moderno. Buenos Aires: Nueva Visión.

Gramsci, A. (2011). Antología. Buenos Aires: Siglo XXI.

Groppo, A. (2011). Los dos príncipes: Juan Perón y Getulio Vargas. Córdoba: Eduvim.

Hobbes, T. (2005). Leviatán. Buenos Aires: Del Libertador.

Ípola, E. de (2009). La última utopía. Reflexiones sobre la teoría del populismo de Ernesto Laclau. En Hilb, C. (comp.). El político y el científico. Ensayos en homenaje a Juan Carlos Portantiero. Buenos Aires: Siglo XXI, pp. 197-220.

Laclau, E. (1985). Tesis acerca de la forma hegemónica de la política. En Labastida, J. (coord.). Hegemonía y alternativas políticas en América Latina. México: Siglo XXI, pp. 19-44.

Laclau, E. (1993). Nuevas reflexiones sobre la revolución de nuestro tiempo. Buenos Aires: Nueva Visión.

Laclau, E. (1996). Emancipación y diferencia. Buenos Aires: Ariel.

Laclau, E. (2003a). Estructura, historia y lo político. En Butler, J., Laclau, E. y Zizek, S. (comps.). Contingencia, hegemonía, universalidad. Diálogos contemporáneos en la izquierda. México: Fondo de Cultura Económica, pp. 185-214.

Laclau, E. (2003b). Identidad y hegemonía: el rol de la universalidad en la constitución de lógicas políticas. En Butler, J., Laclau, E. y Zizek, S. (comps.). Contingencia, hegemonía, universalidad. Diálogos contemporáneos en la izquierda. México: Fondo de Cultura Económica, pp. 49-93.

Laclau, E. (2004) Muerte y resurrección de la teoría de la ideología. En Misticismo, retórica y política, Buenos Aires: Fondo de Cultura Económica, pp. 9-56.

Laclau, E. (2005a). La razón populista. Buenos Aires: Fondo de Cultura Económica.

Laclau, E. (2005b). Deconstrucción, pragmatismo, hegemonía. En Mouffe, C. (comp.), Deconstrucción y pragmatis- mo. Buenos Aires: Espacios del saber, pp. 97-136.

Laclau, E. (2006a). La deriva populista y la centroizquierda latinoamericana. Nueva Sociedad, 205, pp. 56-61.

Laclau, E. (2006b). Consideraciones sobre el populismo latinoamericano. Cuadernos del Cendes, 62, pp. 115-120.

Laclau, E. (2008). Debates y combates. Por un nuevo horizonte de la política. Buenos Aires: Fondo de Cultura Económica.

Laclau, E. (2009). Populismo: ¿qué nos dice el nombre? En: Panizza, F. (comp.). El populismo como espejo de la democracia. Buenos Aires: Fondo de Cultura Económica, pp. 51-70.

Laclau, E. (2014). Los fundamentos retóricos de la sociedad. Buenos Aires: Fondo de Cultura Económica.

Laclau, E. y Mouffe, C. (1987). Hegemonía y estrategia socialista. Buenos Aires: Fondo de Cultura Económica.

Lefort, C. (1990). La invención democrática. Buenos Aires: Nueva Visión.

Lefort, C. (2011). Democracia y representación. Buenos Aires: Prometeo.

Leiras, S. C. (2008). Liderazgo político: estilo (neo)populista, estrategia (neo) decisionista. Hacia un modelo de interpretación en contexto democrático. Ecuador Debate, 73, pp. 47-62.

Lijphart, A. (1984). Democracia en las sociedades plurales. Buenos Aires: GEI.

Macpherson, C. B. (1982). La democracia liberal y su época. Madrid: Alianza.

Manin, B. (1992). Metamorfosis de la representación. En Dos Santos, M. y Calderón, F. (comps.) ¿Qué queda de la representación política? Caracas: Nueva Sociedad, pp. 9-40.

Maquiavelo, N. (1998). El Príncipe. Buenos Aires: Planeta D’Agostini.

Mondolfo, R. (1973). El humanismo de Marx. México: Fondo de Cultura Económica.

Mouffe, C. (1999). El retorno de lo político. Buenos Aires: Paidós.
Mouffe, C. (2007). En torno a lo político. Buenos Aires: Fondo de Cultura Económica.

Novaro, M. (1994). Pilotos de tormentas: crisis de representación y personalización de la política en Argentina. 19891993. Buenos Aires: Letra Buena.

Novaro, M. (2000). Representación y liderazgo en las democracias contemporáneas. Rosario: Homo Sapiens.

Nun, J. (2001). Democracia: ¿gobierno del pueblo o gobierno de los políticos? Buenos Aires: Fondo de Cultura Económica.

O’Donnell, G. (1992). Delegative democracy? Documento de trabajo 172 . Helen Kellog Institute for International Studies, South Bend, University of Notre Dame.

O’Donnell, G. (2001). Accountability horizontal: la institucionalización legal de la desconfianza política. PostData. Revista de reflexión y análisis político, 7, pp. 11-34.

O’Donnell, G. (2007). Disonancias. Buenos Aires: Prometeo.

Pitkin, H. (1985). El concepto de representación. Madrid: Centro de Estudios Constitucionales.

Quiroga, M. V. (2014). Debates y recepciones de la perspectiva laclausiana del populismo. Postdata, 19 (2), pp. 377-394.

Rousseau, J. J. (1995). Contrato Social. Barcelona: Planeta DeAgostini. https://doi. org/10.1007/BF02693328

Sartori, G. (1980). Partidos y sistemas de partidos. Madrid: Alianza.

Schmitt, C. (2005). Teología Política. Buenos Aires: Struhart \& Cía.

Schneider, C. y Welp, Y. (2011). ¿Transformación democrática o control político? Análisis comparado de la participación ciudadana institucional en América del Sur. Íconos, 40, pp. 21-39.

Tocqueville, A. (1969). La democracia en América. Madrid: Guadarrama.

Weber, M. (1984). Economía y sociedad. México: Fondo de Cultura Económica.

Weber, M. (1991). El político y el científico. Madrid: Alianza. 